\title{
PRIMEROS RESULTADOS DE LAS INVESTIGACIONES ARQUEOLÓGICAS EN EL INTERFLUVIO COLORADO-NEGRO (DEPARTAMENTO DE PICHI MAHUIDA, PROVINCIA DE RÍO NEGRO, ARGENTINA) ${ }^{1}$
}

\author{
FIRST RESULTS OF ARCHAEOLOGICAL RESEARCH IN THE \\ COLORADO-NEGRO INTERFLUVIUM (PICHI MAHUIDA DEPARTMENT, \\ RÍO NEGRO PROVINCE, ARGENTINA)
}

\author{
Gustavo Martínez $z^{2}$, Florencia Santos Valero ${ }^{2}$, Ana Paula Alcaráz ${ }^{2}$, Erika Borges Vaz ${ }^{2}$, Luciana \\ Stoessel ${ }^{2}$, Gustavo Flensborg ${ }^{2}$, Gustavo A. Martínez $z^{3}$ y Daniel J. Rafuse ${ }^{2}$
}

En este trabajo se presentan los resultados de las primeras investigaciones arqueológicas realizadas en el interfluvio ubicado entre los cursos medios de los ríos Colorado y Negro (Provincia de Río Negro, Argentina). En esta extensa planicie árida se encuentran lagunas temporarias en las que se concentra el material arqueológico, principalmente en superficie. Con el fin de comprender las estrategias humanas de uso del espacio y la intensidad de las ocupaciones se llevaron a cabo estudios distribucionales y, en menor medida, excavaciones arqueológicas. La información generada fue discutida a la luz de las expectativas arqueológicas derivadas del modelo de uso del espacio propuesto por Borrero y colaboradores (2008). Los resultados obtenidos indican que el registro arqueológico localizado en torno a estas lagunas efímeras es principalmente el efecto de un uso del espacio planificado y redundante. Asimismo, algunos sectores de estas lagunas fueron utilizados más intensa y repetidamente, sugiriendo casos de redundancia específica. Si bien no se cuenta con fechados radiocarbónicos, la presencia de cerámica permite vincular las ocupaciones humanas al menos al Holoceno Tardío. La evidencia discutida revela la importancia de este espacio interfluvial en los circuitos de asentamiento y movilidad de las sociedades cazadoras-recolectoras en torno a dos de los principales ríos norpatagónicos.

Palabras claves: interfluvio, ríos Colorado y Negro, Norpatagonia, Holoceno Tardío, cazadores-recolectores, arqueología distribucional, uso del espacio.

This paper presents the first results of the archaeological investigations carried out in the interfluvium located between the middle courses of the Colorado and Negro rivers (Rio Negro province, Argentina). This is an extensive arid plain with many temporary lagoons in which archaeological material is concentrated, mainly on the surface. Our analysis included distributional studies and, to a lesser extent, archaeological excavations, in order to understand the human strategies of space use and occupational intensity. The generated information is discussed in the light of archaeological expectations derived from the space use model proposed by Borrero and colleagues (2008). The results obtained indicate that the archaeological record located around these ephemeral lagoons is mainly the result of a planned and redundant use of space. Furthermore, some sectors of these lagoons were used more intensively and repeatedly, suggesting cases of specific redundancy. Although radiocarbon dates could not be obtained, the presence of pottery relates human occupations at least to the Late Holocene. The evidence discussed reveals the importance of this interfluvial space in the settlement and mobility strategies of the hunter-gatherer societies that inhabited two of the main northern Patagonian rivers.

Key words: Interfluvium, Colorado and Negro rivers, North Patagonia, Late Holocene, hunter-gatherers, distributional archaeology, use of space.

1 Una primera versión de este trabajo fue presentada en el Simposio Patagonian evolutionary archaeology and human paleoecology: Commending the legacy (still in the making) of Luis Alberto Borrero in the interpretation of hunter-gatherer studies of the Southern Cone, realizado en el marco de la reunión anual 84 de la Society for American Archaeology realizada en Albuquerque, USA (abril 2019). Este manuscrito fue revisado por pares externos y editado por el Comité Editor de Chungara, y César Méndez y Juan Bautista Belardi, editores invitados.

2 Instituto de Investigaciones Arqueológicas y Paleontológicas del Cuaternario Pampeano-Consejo Nacional de Investigaciones Científicas y Técnicas (INCUAPA-CONICET), Facultad de Ciencias Sociales, Universidad Nacional del Centro de la Provincia de Buenos Aires (UNICEN), Olavarría, Argentina. gmartine@soc.unicen.edu.ar; fsantosvalero@gmail.com; aalcaraz@soc.unicen.edu.ar; borgesvaze@gmail.com; 1stoesse@soc.unicen.edu.ar; gflensbo@soc.unicen.edu.ar; drafuse@soc.unicen.edu.ar 3 Instituto de Geología de Costas y del Cuaternario, Universidad Nacional de Mar del Plata (IGCYC-UNMDP-CIC), Mar del Plata, Argentina.gustavo.gmarti@gmail.com

Recibido: abril 2020 Aceptado: octubre 2020. 
Las investigaciones arqueológicas en la transición Pampeano-Patagónica oriental y en el noreste de Patagonia se han concentrado en torno a las cuencas de los principales ríos (p.ej., Colorado y Negro), en el sector de planicies y bajos del centro de la Provincia de Río Negro y en la costa Atlántica (Borella et al. 2015; Carden y Prates 2015; Eugenio y Aldazabal 2004; Favier Dubois 2013; Favier Dubois et al. 2009; Mange 2019; Mange et al. 2016; Martínez 2017; Martínez et al. 2017;
Prates 2008; Prates y Mange 2016; Prates et al. 2019; ver citas en estos trabajos por una revisión histórica de los antecedentes arqueológicos de estas microrregiones). Mientras que en los últimos 20 años se han estudiado, desde un enfoque interdisciplinario, diversos aspectos de la vida de los grupos cazadores-recolectores que habitaron estos sectores (Martínez 2017), las planicies ubicadas entre los cursos medios de los ríos Colorado y Negro (Provincia de Río Negro) (Figura 1) permanecen

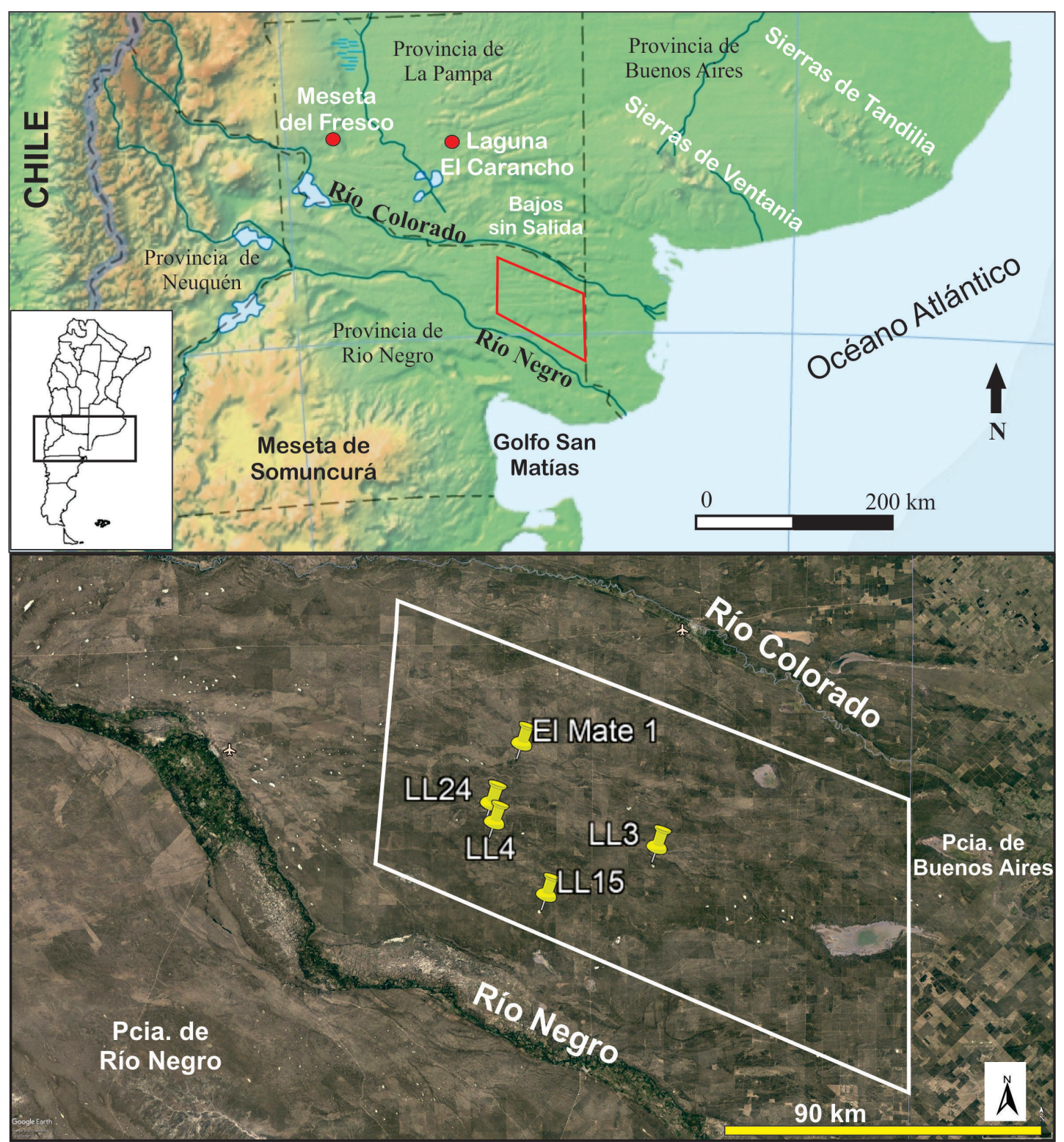

Figura 1. Área del interfluvio Colorado-Negro (Provincia de Río Negro) en el ámbito pampeano y norpatagónico. En la imagen se observan los sitios detectados y los cuerpos lagunares diseminados en el área de estudio.

Area of the Colorado-Negro interfluvium (Río Negro Province) as part of the Pampa and North-Patagonian region. Images show the detected sites and lagoons scattered throughout the study area. 
desconocidas arqueológicamente. Uno de los rasgos destacados de este interfluvio es la ausencia de agua superficial permanente, aunque presenta cuerpos lagunares temporarios, localizados en bajos o en la intersección de estos con antiguos cauces fluviales. En este trabajo se presentan las características del registro arqueológico que se manifiesta principalmente en la superficie de sectores próximos a estos cuerpos lagunares, entre los que sobresalen los artefactos líticos, con escasísima presencia de otros ítems arqueológicos.

En la arqueología de Fuego-Patagonia, se encuentran numerosos ejemplos de distribuciones superficiales de materiales arqueológicos en torno a lagos y lagunas someras, ya sean permanentes o temporarias, asociadas a distintos contextos geomorfológicos. Este registro, comúnmente caracterizado por palimpsestos, ha llevado al desarrollo de estudios distribucionales, geomorfológicos, geoarqueológicos, de procesos de formación del registro arqueológico, líticos, arqueofaunísticos y tafonómicos (Belardi et al. 2019; Borrazzo et al. 2019; Borrero et al. 2013; Charlin et al. 2011; Oría y Salemme 2019; Oría et al. 2015; Peralta González y Moreno 2019; Svoboda y Moreno 2018, entre muchos otros). Los aportes de Luis Borrero a estos temas han sido centrales en la generación y fortalecimiento de líneas de investigación arqueológicas desde una perspectiva biogeográfica (Borrero 1989), con metodologías distribucionales (Borrero et al. 1992) que, junto con la tafonomía regional (Borrero 1988), sentaron las bases para la consolidación de este tipo de aproximaciones.

El objetivo de este trabajo es dar a conocer los primeros resultados arqueológicos obtenidos a partir de los estudios realizados en el interfluvio ubicado entre los cursos medios de los ríos Colorado y Negro (Provincia de Río Negro), con el propósito de entender las formas de uso del espacio, así como la duración e intensidad de las ocupaciones por parte de grupos cazadores-recolectores. Se busca comprender aspectos ligados a la organización de la tecnología lítica, la movilidad y los sistemas de asentamiento. Para este propósito se llevaron a cabo principalmente estudios distribucionales y, en menor medida, excavaciones arqueológicas. A través de la aplicación de un sistema de información geográfica (SIG), se analizaron las distribuciones espaciales de artefactos superficiales, su densidad y formas. Dado el predominio de los artefactos líticos, se realizaron estudios tecno-tipológicos y de secuencias de producción que, en conjunción con el enfoque distribucional, permitieron discutir los objetivos antes propuestos. Asimismo, se presentan resultados faunísticos y de tecnología cerámica. A esto se suman los estudios geoarqueológicos y geomorfológicos que permitieron entender aspectos ligados a los procesos de formación del registro arqueológico, su resolución e integridad, así como aspectos cronológicos de las formaciones geológicas y de las ocupaciones humanas.

El fin último de este trabajo es evaluar si este espacio interfluvial fue utilizado como un área de tránsito y/o circulación por parte de poblaciones humanas o si fue objeto de ocupaciones más permanentes, sistemáticas y estables (p.ej., residenciales). Asimismo, se analiza cómo fue la vinculación entre los espacios ribereños y el interfluvio.

\section{Ambiente y Geomorfología}

El área de estudio $\left(39^{\circ} 20^{\prime}-40^{\circ} 27^{\prime} \mathrm{LS}-63^{\circ} 23^{\prime}-65^{\circ}\right.$ $15^{\prime}$ LO) (Figura 1) se caracteriza por un clima árido y templado-frío (árido mesotermal). Las precipitaciones oscilan entre los 100 y $300 \mathrm{~mm}$ anuales y la temperatura entre $1{ }^{\circ} \mathrm{C}$ a $32{ }^{\circ} \mathrm{C}$, aunque en condiciones extremas puede variar entre los $-5{ }^{\circ} \mathrm{C}$ y $38{ }^{\circ} \mathrm{C}$. En general, los vientos tienen una dirección predominante de oeste a este. El periodo octubre-marzo acumula las mayores lluvias, siendo abril-septiembre la época más seca. Se trata de un área donde no hay disponibilidad superficial permanente de agua dulce. De acuerdo con la información actual, las lagunas que están presentes en ella se encuentran generalmente secas, aunque se forman depósitos de agua dulce luego de las lluvias. Las comunidades vegetales pertenecen al monte oriental o de transición (Cabrera 1976; ver Mange 2019:25), una estepa de arbustos y pastos duros donde se registran Geoffroea decorticans (chañar), Prosopis caldenia (caldén), Prosopis flexuosa (algarrobo), Condalia microphylla (piquillín), Prosopis alpataco (alpataco), Larrea spp. (jarilla), Chuquina gaerinacea (uña de gato), Stipa spp. (paja vizcachera) y gramíneas. La fauna corresponde al dominio Patagónico, con presencia de Lama guanicoe (guanaco), Rhea americana (ñandú), Puma concolor (puma), Dolichotis patagonum (mara), Lagostomus maximus (vizcacha), Chaetophractus villosus (peludo), Zaedyus pichiy (piche), entre otros (Mange 2019; Ringuelet 1961).

La siguiente descripción geomorfológica fue extractada de la Hoja Geológica 3966-IV, Choele Choel, Provincia de Río Negro (Escosteguy et al. 2011), donde se encuentra el área de estudio. El paisaje actual fue modelado casi en su totalidad por el accionar de procesos fluviales y, en menor medida, eólicos y de remoción en masa. Se reconocen 
dos unidades geomorfológicas bien diferenciadas: (a) la planicie aluvial actual y las terrazas del Río Negro y (b) un relieve mesetiforme conformado por extensas planicies estructurales. Los sitios objeto de estudio se encuentran en esta última (Figura 2). La geomorfología del área de estudio está formada por niveles mesetiformes cuyo sustrato regional son las arenas y areniscas grises azuladas de la Formación Río Negro de edad Mioceno Tardío-Plioceno Tardío (Andreis 1965). Esta formación aflora en las barrancas del Río Negro y en los bordes de los Bajos sin Salida más profundos. Su base está compuesta por una secuencia donde alternan bancos de arcilitas y limolitas de color castaño oscuro con areniscas grises, finas a medianas. Por encima de esta formación, y en discordancia erosiva, se encuentran depósitos fluviales gruesos, denominados conglomerados polimícticos, de edad pliocena y pleistocena. Se trata de los Rodados Patagónicos (Darwin 1846) o Tehuelches, a los que se les han asignado orígenes diversos. Si bien Fidalgo y Riggi (1970) proponen para su formación procesos variados relacionados principalmente con pedimentación, acción fluvial y remoción en masa, actualmente hay cierto consenso en cuanto a su origen fluvial (Cortelezzi et al. 1968; Escosteguy et al. 2011; Groeber 1936). Para el área de estudio, Escosteguy y colaboradores (2011) los han denominado Depósitos Fluviales Gruesos, ya que

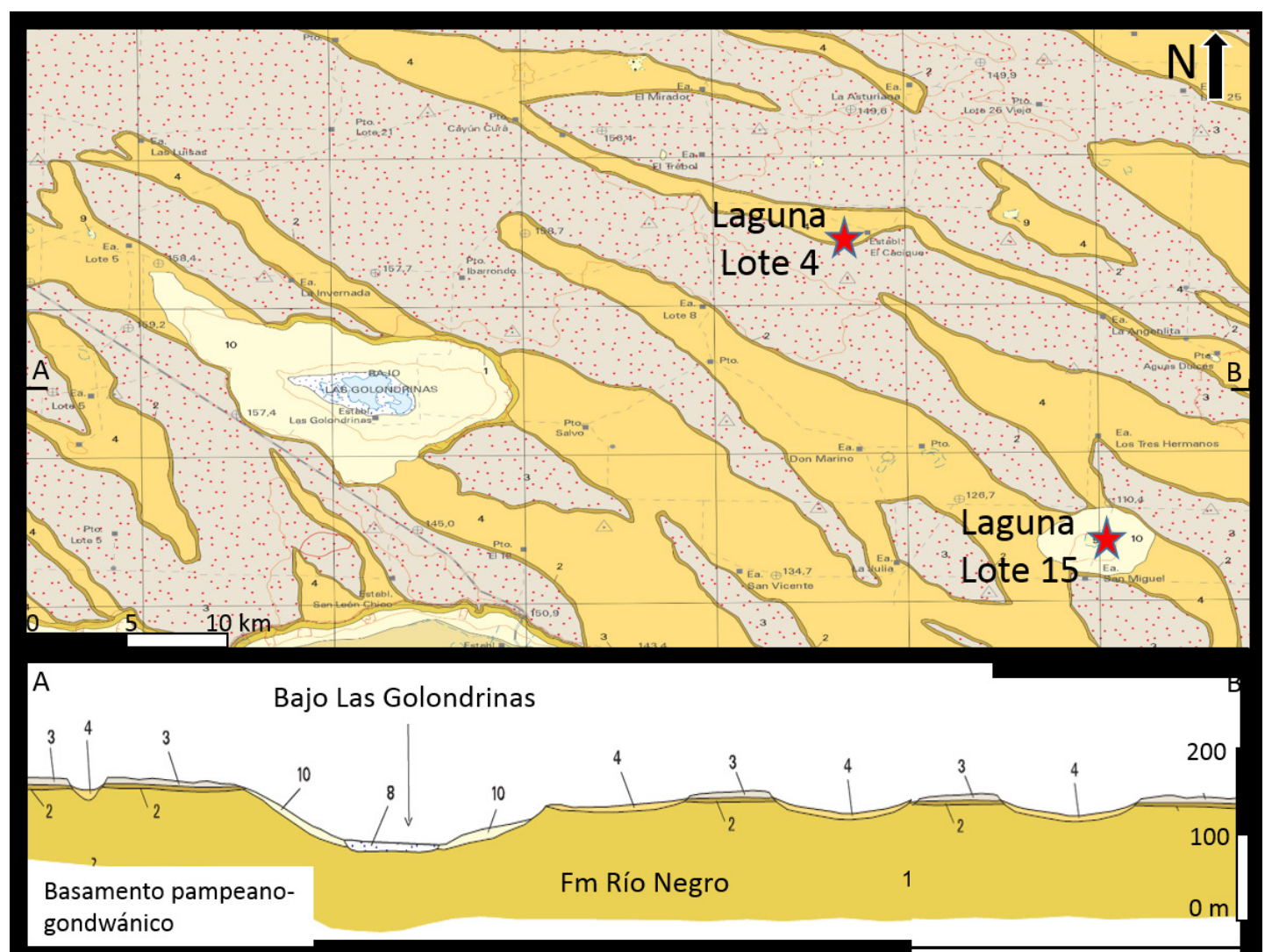

Figura 2. Arriba: Ubicación de los sitios (LL4 y LL15) sobre el mapa geológico del IGN. A-B: traza del perfil geológico. Debajo: perfil geológico mostrando la distribución vertical de las unidades aflorantes. Las principales son: (1) Fm Río Negro, (2) Depósitos fluviales gruesos (conglomerados polimícticos), (3) Calcrete, (4) Depósitos aluviales antiguos, (8) Depósitos evaporíticos, (10) Depósitos aluviales y coluviales indiferenciados. Sobre estas unidades se depositan los mantos eólicos.

Above: Location of sites (LL4 and LL15) on the geological map taken from the IGN (Instituto Geografico Nacional). A-B: trace of geological profile. Below: geological profile showing the vertical distribution of outcropping units. The main ones are: (1) Río Negro Formation, (2) Coarse river deposits (polymictic conglomerates), (3) Calcrete, (4) Ancient alluvial deposits, (8) Evaporitic deposits, (10) Undifferentiated alluvial and colluvial deposits. Aeolian mantles are deposited on all of these units. 
la denominación de Rodados Patagónicos involucra a más de una entidad geomorfológica mapeable en todo el ámbito patagónico. Estos conglomerados se intercalan con bancos de areniscas. Son clastos imbricados, con una estratificación grosera que puede ser paralela o entrecruzada planar. La morfología de los clastos es redondeada a subredondeada y prolada, de tamaños que varían entre 1 y $10 \mathrm{~cm}$, aunque excepcionalmente pueden llegar a medir $20 \mathrm{~cm}$. Su composición litológica abarca andesitas, basaltos, riolitas, granitos, cuarzo, sílices, calcedonias, etc. Las porciones superiores de esta unidad están fuertemente cementadas por carbonatos. Estos depósitos fueron generados como parte de un ambiente fluvial de alta energía producto de una red de drenaje distributaria y de bajos endorreicos alargados en el sentido de la pendiente regional (Escosteguy et al. 2011). La cronología inferida para este sistema fluvial incluye el rango Plioceno Medio-Pleistoceno. En algunos sectores estos depósitos son cubiertos por un calcrete de edad Pleistocena, que se encuentra muy próximo a la superficie y está cubierto por depósitos aluviales antiguos, producto de paleocanales derivados de redes de drenaje no funcionales (González Díaz y Malagnino 1984). Hacia el tope de la secuencia regional, y en discordancia erosiva, se reconocen depósitos eólicos de edad Pleistoceno-Holoceno. Forman un manto delgado o pequeñas dunas que se ubican sobre algunas de las unidades antes mencionadas. Los depósitos eólicos de tipo mantiforme se hallan coronando la meseta, tienen espesores que varían entre 30 y 80 $\mathrm{cm}$, son bastante homogéneos, sin estratificación, de granulometría fina (p.ej., arenas limosas eólicas) y suelen presentar abundante carbonato de calcio pulverulento y pequeños clastos oscuros diseminados, redondeados, de hasta $0,3 \mathrm{~cm}$ (Escosteguy et al. 2011). Los depósitos eólicos que forman dunas se ubican principalmente en las zonas deprimidas. En general las dunas tienen alturas que oscilan entre $1 \mathrm{y}$ $3 \mathrm{~m}$, están compuestas por arenas medianas a finas y en su mayoría poseen cobertura vegetal. Un rasgo característico del área de estudio son los Bajos sin Salida (p.ej., Bajo Las Golondrinas; Figura 2), que se ubican sobre las redes de drenaje de antiguos paleocanales, cortando los niveles mesetiformes labrados sobre las areniscas de la Formación Río Negro (Figura 2). Dichos bajos presentan formas y profundidades variables, de conformación generalmente elíptica e irregular. Su red de drenaje es endorreica y en sus partes más profundas contienen barreales, salitrales o lagunas temporarias.
Las unidades de los bajos son depósitos evaporíticos, aluviales finos y aluviales y coluviales indiferenciados. El origen de los bajos es aún objeto de discusión, aunque se considera un origen multigenético, en el que la deflación habría sido el principal proceso, con la participación de erosión hídrica y de remoción en masa, que habrían favorecido la meteorización y desagregación de las sedimentitas neógenas de la Formación Río Negro (Escosteguy et al. 2011 y citas allí mencionadas).

\section{Principales Características de los Sitios Relevados}

Como se comentó anteriormente, el área de estudio (Figura 1) careció de antecedentes arqueológicos hasta el inicio de este proyecto. En el año 2013 comenzaron las prospecciones con el reconocimiento de cinco lagunas con presencia de material arqueológico superficial. Las lagunas son El Mate 1, Lote 24, Lote 4, Lote 15 y Lote 3 (Figura 1). En todos los casos se observó que el registro arqueológico se concentra en derredor de estas lagunas efímeras y está casi exclusivamente compuesto por materiales líticos $\mathrm{y}$, eventualmente, por unos pocos tiestos cerámicos.

Dada la cantidad y distribución del material observado, se seleccionaron la laguna del Lote 4 (LL4) (39॰31'20.39''LS; 6446'11.76' 'LO) y la del Lote 15 (LL15) (3942'21.85',LS; 64³6'17.31',LO) para llevar a cabo trabajos de campo sistemáticos. La selección de las mismas también se realizó en función de su relativa cercanía espacial (ca. $25 \mathrm{~km}$ ), teniendo en consideración que en futuros trabajos de campo el espacio que separa a ambas lagunas también debe ser objeto de un análisis distribucional, a los efectos de entender de manera más acabada el uso del interfluvio en una escala espacial mayor.

La LL4 se ubica en un bajo, sobre el borde de un paleocanal (Figura 2). Es una depresión elongada en sentido ENE-OSO, de $4 \mathrm{~km}$ de longitud x 1,5 km de ancho y un desnivel relativo de $11 \mathrm{~m}$. En su centro se presenta una laguna temporaria, con sedimentos superficiales arcillosos y depósitos salobres, que tiene una morfología similar a la de la depresión que la contiene, con una dimensión de $890 \mathrm{~m}$ x $350 \mathrm{~m}$. La LL15 está en un bajo que se desarrolló a expensas de dos paleocanales que se intersectan (Figura 2). La depresión es subcircular y tiene ca. $4,5 \mathrm{~km}$ en sentido $\mathrm{N}-\mathrm{S}$ y $6,5 \mathrm{~km}$ en sentido O-E, con un desnivel relativo de $40 \mathrm{~m}$. El cuerpo inundable central es circular y tiene $900 \mathrm{~m}$ de diámetro. 


\section{Aspectos Conceptuales y Metodológicos}

Dentro de un marco que considera variables ecológicas, biogeográficas y sociales, en lo referido al estudio de los modos de circulación humana e intensidad en el uso del espacio por grupos cazadoresrecolectores del pasado, se utilizará el modelo general propuesto por Borrero y colaboradores (2008). El mismo incluye dos componentes: asentamientos "programados" y asentamientos "al paso". El modelo contempla el análisis de variables tales como las frecuencias de hallazgos, la intensidad de uso del espacio, la localización de asentamientos en relación con los recursos principales y su continuidad ocupacional. Las expectativas arqueológicas de ambos componentes son mencionadas y discutidas en las conclusiones, donde son puestas en conjunción con los resultados obtenidos en este trabajo. Para el análisis de los dos componentes del modelo, es central la noción de redundancia en sus dos dimensiones principales: específica y genérica (Hietala y Stevens 1977). En el caso de la redundancia específica, un mismo locus de una zona en particular (p.ej., algún sector puntual de la costa de una laguna) es reiteradamente utilizado a través del tiempo y existen factores de localización (p.ej., atractores) estrictos que producen una alta congruencia espacial de las ocupaciones. En cambio, la redundancia genérica remite al uso de la misma zona (p.ej., todo el sector costero de una laguna), pero en diferentes loci, con baja congruencia espacial debida a factores de localización laxos (Belardi 2003:5758; Dewar y McBride 1992:231-236). Ambos tipos de redundancia siempre requieren de definiciones operativas en función de la escala de análisis espacial bajo estudio.

El trabajo de campo fue realizado siguiendo el enfoque de la arqueología distribucional (Borrero et al. 1992; Dunnell y Dancey 1983; Ebert 1992; Thomas 1975, entre otros), también denominada "off site archaeology" (Foley 1981), como estrategia para obtener información de las características estructurales del registro arqueológico. Este es percibido como una distribución relativamente continua de artefactos en el espacio y promediado temporalmente (Dunnell y Dancey 1983), y su estudio permite conocer la intensidad y el uso diferencial de determinados espacios por parte de los grupos humanos (Binford 1979; Borrero et al. 1992). La unidad mínima de análisis considerada es el artefacto (Thomas 1975) y a partir de esta se puede conocer la densidad de hallazgos, las formas distribucionales, las clases artefactuales y su jerarquización en el espacio (Belardi 2003; Borrero et al. 1992; Carballo Marina 2007; Zubimendi 2010, 2015; Zubimendi y Ambrústolo 2017).

Los trabajos sistemáticos en el área de estudio bajo este enfoque distribucional fueron realizados en los meses de febrero de los años 2018 y 2019 y consistieron en dos actividades puntuales. Por una parte, se realizaron transectas sistemáticas alrededor de las lagunas y en sectores cercanos a las mismas. A lo largo de cada transecta se consideraron intervalos de $25 \mathrm{~m}$ como unidades de recolección. En el caso de las márgenes de las lagunas, se realizaron tres transectas con un ancho de $10 \mathrm{~m}$ cada una. En el caso de los sectores adyacentes al cuerpo lagunar, tres transectas en LL4 y seis en LL15. Todas ellas se ubicaron en caminos para vehículos (Figura 3) y tuvieron un ancho de $6 \mathrm{~m}$ cada una. Esto último fue realizado con el propósito de evaluar la presencia de artefactos y la distribución del registro arqueológico en superficies con buena visibilidad y que comprenden sectores que se alejan progresivamente de las lagunas. Las variables tomadas en cuenta al momento de relevar las condiciones del terreno donde se realizaron las transectas fueron: ambiente sedimentario (arenoso, limoso), pendiente (nula, baja, media y alta), potencial de enterramiento (nulo, bajo y alto), tipo y distribución de vegetación (monte, pastizales, etc.), acción antrópica actual (caminos, alambrados, terraplenes, ganadería), visibilidad arqueológica en función del porcentaje de cobertura vegetal $($ mala $=76-100 \%$; regular $=51-75 \%$; buena $=26-50 \%$; muy buena $=1-25 \%$; excelente $=\sin$ cobertura vegetal), y presencia-ausencia de artefactos (ver Belardi 2003; Borrero et al. 1992). Con base en la frecuencia de artefactos registrados en cada unidad de recolección, se utilizó la siguiente clasificación: (a) sin hallazgos; (b) hallazgos aislados (solo una pieza); (c) concentraciones (conjuntos de entre dos y 24 artefactos) y (d) sitios (25 artefactos o más) (Borrero et al. 1992).

La densidad arqueológica se definió sobre la base de la cantidad de artefactos por unidad de recolección (artefactos/metros cuadrados). Según los resultados obtenidos (ver debajo) y a los fines analíticos de este trabajo, la densidad de artefactos fue categorizada como Baja: 0,001-0,009; Media: 0,01-0,09; Alta: 0,1-0,9 y Muy Alta: >1. Para construir mapas de densidad artefactual, la información obtenida de cada transecta fue ingresada en un Sistema de Información Geográfica (SIG) mediante el software QGIS (versión 3.4.15; QGIS Development Team 2019). El análisis de datos obtenido por QGIS se basó en dos pasos. En 


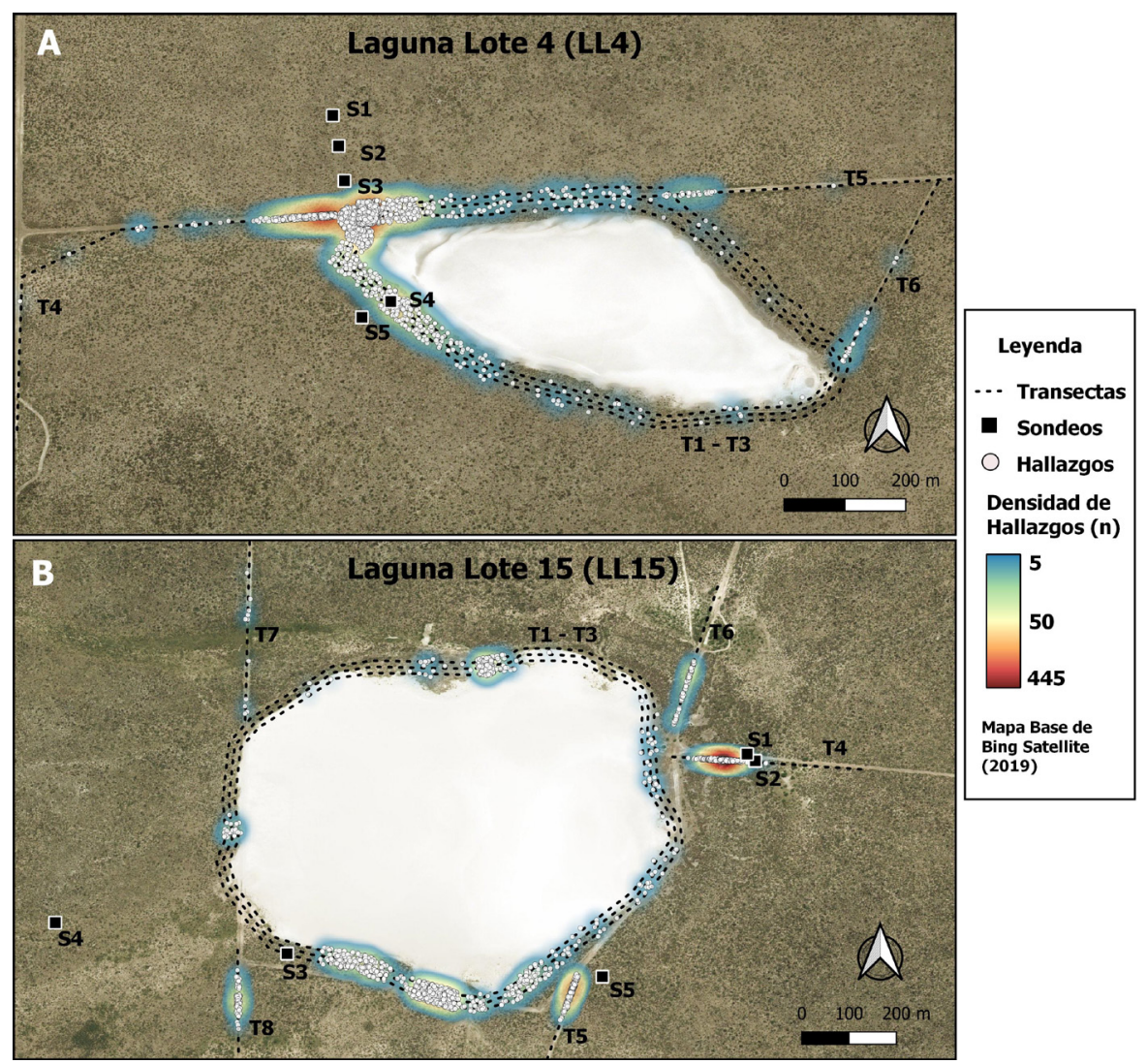

Figura 3. Localización de las transectas y sondeos realizados en LL4 (A) y LL15 (B). Los puntos refieren a hallazgos y los colores, a la densidad según el método kernel (Baxter et al. 1997).

Location of transects and test pits carried out at LLA (A) and LL15 (B). The points refer to the findings and the colors to the density according to the kernel method (Baxter et al. 1997).

primer lugar, la generación de puntos aleatorios en función del número total de hallazgos recuperados en cada intervalo de $25 \mathrm{~m}$. Para esto, se utilizó el algoritmo preinstalado de "Puntos Aleatorios Dentro de Polígonos". En segundo lugar, con los puntos aleatorios se generó un mapa de estimación de densidad de kernel (Baxter et al. 1997) con un radio de $50 \mathrm{~m}$. Para esto, se utilizó el complemento de QGIS "Mapa de Calor" (Heatmap). Finalmente, teniendo en cuenta la frecuencia y la densidad artefactual se analizó la forma en que se distribuyeron los artefactos a lo largo de las transectas, pudiendo ser formas homogéneas o heterogéneas (Zubimendi y Ambrústolo 2017).

Por otro lado, después de realizar las transectas se eligieron algunos sectores alrededor de las lagunas, principalmente aquellos con mayor densidad artefactual, para realizar sondeos (Figura 3). Esto fue llevado a cabo con la finalidad de constatar la probable presencia de artefactos en estratigrafía y su relación con aquellos hallados en superficie. Se excavaron cinco sondeos (1 x $1 \mathrm{~m})$ en cada laguna sobre pequeños mantos eólicos, siguiendo niveles artificiales de $10 \mathrm{~cm}$ y tamizando todo el sedimento extraído.

Todos los artefactos hallados tanto en superficie como en estratigrafía fueron recuperados para su análisis en el laboratorio. El material lítico fue analizado desde una perspectiva tecnomorfológica (Aschero 1975, 1983; Bellelli et al. 1985-1987) y tecnológica (Inizan et al. 1995; Marchand 1999; Turq 2000 , entre otros). En el primer caso, el objetivo fue conocer las materias primas explotadas, las categorías artefactuales representadas y las características de los artefactos recuperados. En el segundo caso, se evaluaron las etapas de producción representadas en los conjuntos, así como aquellos métodos y técnicas de talla empleados para el trabajo de las rocas en función de establecer tendencias tecnológicas generales ${ }^{1}$ (Inizan et al. 1995; Marchand 1999; Turq 2000, entre otros). 
La identificación de las materias primas se llevó a cabo considerando estudios realizados en áreas adyacentes, como el valle inferior del Río Colorado y el valle medio del Río Negro (Armentano 2012; Mange 2019; Martínez y Santos Valero 2020; Prates 2008; Santos Valero 2017, entre otros) y en las subregiones Pampa Húmeda, Pampa Seca y otros sectores de Norpatagonia (Alberti y Cardillo 2015; Bayón et al. 1999; Carrera Aizpitarte 2014; Catella 2014, entre otros). Dado que no existen antecedentes de trabajos arqueológicos en el área de estudio, de manera heurística la procedencia de las materias primas fue considerada según dos categorías: locales y exóticas. Mientras la identificación de las primeras se realizó de manera macroscópica, en el caso de las segundas se incluyó también información de cortes delgados de rocas recuperadas en el curso inferior del Río Colorado (Martínez y Santos Valero 2020). Las rocas consideradas locales incluyen rodados de distintas litologías (p.ej., rocas silíceas, basalto/ andesita, calcedonia, riolita, dacita, entre otras) obtenidos en depósitos localizados en las márgenes del Río Negro (Bonomo y Prates 2014; Mange 2019; Prates 2008), a ca. 20-30 km de los sitios analizados. En el sector medio de este río, los rodados fluviales se encuentran disponibles a lo largo de las márgenes y poseen tamaños que oscilan entre 3 y $15 \mathrm{~cm}$ de diámetro, aunque eventualmente pueden alcanzar los $22 \mathrm{~cm}$ (Bonomo y Prates 2014:80). Con respecto a los rodados patagónicos, si bien la bibliografía geológica señala su presencia en el área de estudio (ver apartado de Ambiente y Geomorfología), estos depósitos se encuentran cubiertos por extensos mantos de calcrete, areniscas rionegrenses y sedimentos eólicos (Figura 2, Figura 4A, B y C), estando inaccesibles superficialmente. Aunque durante las prospecciones se identificaron canteras modernas de explotación de rodados (Figura 4A) en las cercanías de los sitios analizados, hasta el momento no se han registrado afloramientos superficiales de los mismos, aunque no se descarta su posible existencia. En estas canteras modernas los rodados se encuentran a profundidades

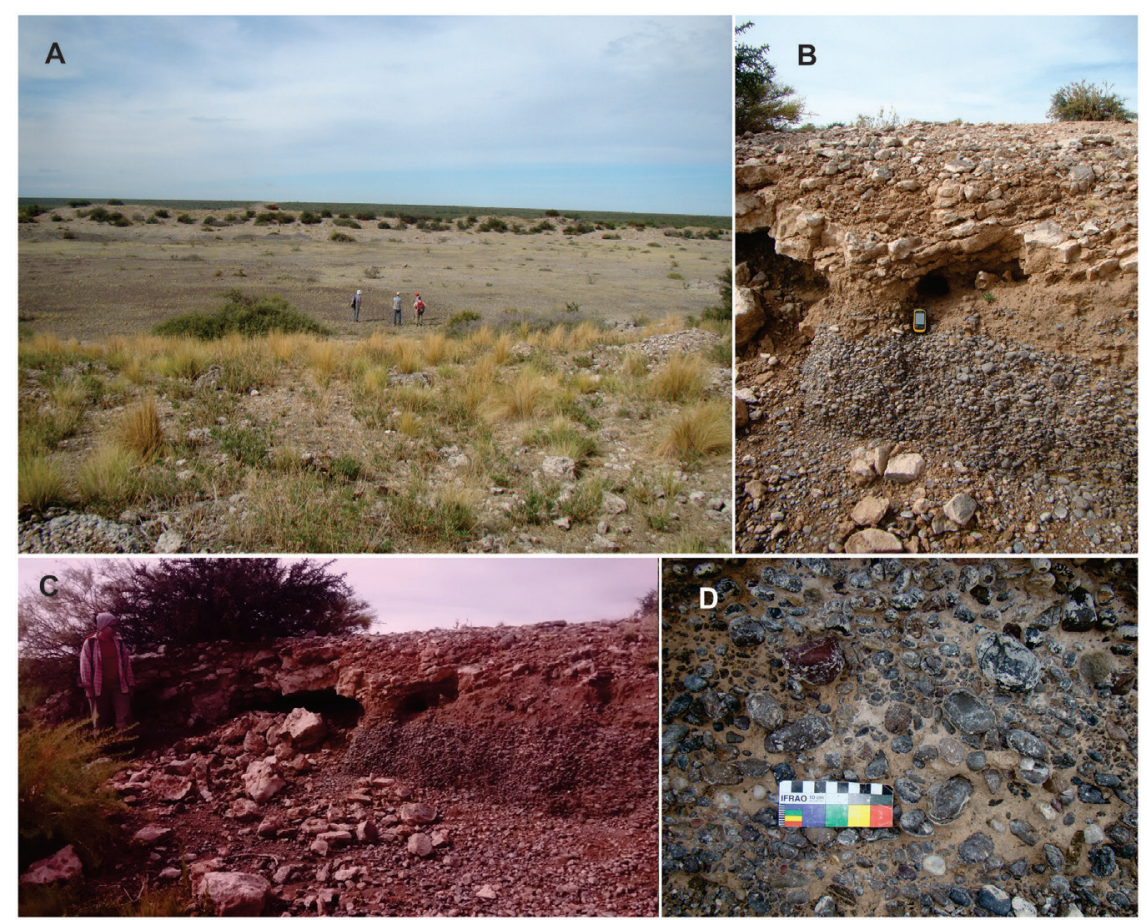

Figura 4. (A) Vista general de una cantera moderna excavada en el paisaje de planicies: (B y C) Depósitos de rodados debajo de una unidad de calcrete y de tosca a una profundidad de ca. $1 \mathrm{~m}$ respecto de la superficie actual del suelo; (D) Detalle de un conglomerado polimíctico con cemento calcáreo.

(A) General view of a modern quarry excavated on the plains: (B and C) Pebble deposits below a unit composed of calcrete and caliche at a depth of ca. $1 \mathrm{~m}$ with respect to the current soil surface; (D) Closeup of a polymictic conglomerate with calcareous cement. 
promedio de al menos $1 \mathrm{~m}$ desde la superficie (Figura 4B y C), formando conglomerados polimícticos con cemento calcáreo (Figura 4D).

Dado el tamaño de los artefactos registrados en los sitios (ver debajo), es difícil sostener un aprovisionamiento desde el curso medio del Río Colorado, que se encuentra a ca. $90 \mathrm{~km}$ de 10 s mismos. En este sector, los tamaños de los rodados predominantes son menores a $3 \mathrm{~cm}$ (Blasi 1991; ver discusión en Armentano 2012). En el caso de las materias primas exóticas, algunas de las rocas registradas provendrían de Tandilia (ortocuarcita), Ventania (metacuarcita y arenisca cuarzosa), los Bajos sin Salida (sílice sedimentario), la Meseta del Fresco (chert silíceo), el Golfo San Matías y/o la meseta de Somuncurá (calcedonia translúcida en ambos casos) (ver Martínez y Santos Valero 2020), en un rango de distancia que oscila entre 120 y $550 \mathrm{~km}$.

Respecto al conjunto faunístico, se llevaron a cabo determinaciones anatómicas y taxonómicas y se efectuaron cuantificaciones (NISP, MNI) (Lyman 2008). Asimismo, se realizó el análisis de las superficies óseas teniendo en cuenta distintas variables tafonómicas (p.ej., meteorización, deterioro químico, depositaciones químicas, abrasión, acción de raíces, huellas de corte, alteración térmica, etc.) a los efectos de evaluar las causas de ingreso de los restos a los depósitos (Andrews 1990; Binford 1981). El análisis del conjunto cerámico se llevó a cabo macroscópicamente de acuerdo a los criterios convencionales propuestos por Shepard (1956), Rye (1981), Rice (1987), Orton et al. (1997), a partir de los cuales se relevaron características tecnológicas referidas al tratamiento de superficies, decoración, atmósfera de cocción, espesor de paredes, entre otros (para más detalle ver Borges Vaz 2017 y referencias allí citadas). Los análisis texturales sobre sedimento fueron realizados en el Laboratorio de Geomorfología y Geología del Cuaternario (CADIC-CONICET) y los químicos, en el Laboratorio de pretratamiento de muestras para análisis isotópicos (LAPREI-INCUAPA-CONICET).

\section{Resultados}

\section{El registro de superficie}

\section{Distribuciones y densidad artefactual}

En LL4 se realizaron seis transectas de extensión variable (Figura 3) cubriendo una extensión de $83.700 \mathrm{~m}^{2}$ y se recuperaron 1844 artefactos (densidad de 0,02203 artefactos por $\mathrm{m}^{2}$ ). En este caso predominan los materiales líticos $(99,8 \%)$, con escasa representación de cerámica $(0,2 \%)$ y ausencia de restos faunísticos.

En esta laguna el ambiente sedimentario es areno-limoso, el potencial de entierro es bajo, y la pendiente del terreno, nula. En líneas generales, predomina la visibilidad regular $(64,3 \%)$, seguida de mala $(14,2 \%)$, muy buena $(10,1 \%)$, excelente $(8,8 \%)$ y buena $(2,5 \%)$. En este sentido, la superficie se caracterizó principalmente por la presencia de arbustos, pastizales y monte, excepto en los caminos, donde la cobertura vegetal fue mínima. Se detectaron artefactos en un rango de categorías de visibilidad que va desde regular a excelente.

La distribución de los artefactos en el espacio en función de los intervalos indica que predomina la categoría sin hallazgos $(44,2 \%)$, seguida por las concentraciones $(30,8 \%)$, en menor medida hallazgos aislados $(13,3 \%)$ y sitios $(11,7 \%)$. El análisis de la densidad artefactual da cuenta de un predominio de la categoría baja $(52,3 \%)$, seguida por la media $(35,8 \%)$ y, en menor medida, alta $(10,4 \%)$ y muy alta $(1,5 \%)$. La distribución de materiales es heterogénea y variable a lo largo de las transectas. Los resultados de los mapas de densidad muestran distintos agrupamientos de artefactos (Figura 3A). La mayor densidad está ubicada en el sector oeste de la laguna $(n=1.702 ; 92,3 \%)$. Aquí, se identificaron dos concentraciones ("puntos calientes") compuestas por 1.137 artefactos (61,7\% del número total de artefactos). Estas concentraciones que abarcan ca. $10.000 \mathrm{~m}^{2}$ están ubicadas sobre y/o en adyacencias de un camino con visibilidad excelente a regular. De acuerdo a la Figura 3A, la densidad de artefactos es menor hacia los sectores norte $(n=79$; $4,3 \%)$, sur $(n=25 ; 1,4 \%)$ y este $(n=22 ; 1,2 \%)$, para una superficie de ca. $53.000 \mathrm{~m}^{2}$. Fuera del entorno de la laguna, el número de artefactos disminuye en todas las direcciones $(\mathrm{n}=18 ; 0,8 \%)$. En las transectas que se alejan del borde de la laguna, las cuales poseen visibilidad excelente, se observa que a partir de los ca. $150 \mathrm{~m}$ los artefactos están escasamente representados (Figura 3A). De hecho, el artefacto registrado a mayor distancia de la laguna se encuentra a $600 \mathrm{~m}$ hacia el oeste.

En la LL15 se realizaron ocho transectas cubriendo una superficie de $125.700 \mathrm{~m}^{2}$ y se recuperaron 1.939 artefactos (densidad de 0,015425 artefactos por $\mathrm{m}^{2}$ ), predominando los materiales líticos $(99,5 \%)$, seguidos por fragmentos cerámicos $(0,5 \%)$ y con ausencia de restos óseos. Como se observó en el caso anterior, el ambiente sedimentario es areno-limoso, el 
potencial de entierro es bajo y la pendiente del terreno, principalmente nula, aunque un sector de la zona norte presentó pendiente baja. Si bien la visibilidad fue variable, predominan las categorías regular $(46,5 \%)$ y buena ( $42 \%)$, seguidas por excelente $(6,1 \%)$ y mala $(5,4 \%)$. En este caso también hubo predominio de arbustos, pastizales y monte, excepto por los caminos, donde existió escasa o nula cobertura vegetal.

La distribución de los artefactos en el espacio en función de los intervalos indica que prevalece la categoría sin hallazgos $(47,6 \%)$, seguida por las concentraciones $(28,4 \%)$ y, en menor medida, hallazgos aislados $(12,6 \%)$ y sitios $(11,4 \%)$. El análisis de la densidad artefactual da cuenta de un predominio de la categoría baja $(50,6 \%)$, seguida por media $(33,3 \%)$ y, en menor medida, alta $(13,8 \%)$ y muy alta $(2,3 \%)$. La distribución de materiales es heterogénea alrededor de la laguna y la densidad de artefactos varía notablemente a lo largo de las transectas. De acuerdo con el mapa de densidad (Figura 3B), un "punto caliente" se ubica al este ( $\mathrm{n}=797 ; 41,1 \%)$, donde se identificó una concentración de 676 artefactos (34,9\% del número total de artefactos) en ca. $800 \mathrm{~m}^{2}$, sobre un camino.
En tanto que en el sector sur de la laguna también se observó una importante concentración de artefactos $(\mathrm{n}=983 ; 50,7 \%)$ en una superficie de ca. $24.000 \mathrm{~m}^{2}$, sobre caminos y áreas arbustivas. Las densidades de artefactos son menores en los sectores norte $(n=133$; $6,9 \%)$ y oeste $(n=25 ; 1,3 \%)$ para una superficie de ca. $68.000 \mathrm{~m}^{2}$. En aquellas transectas que se alejan del borde de la laguna, que poseen una buena visibilidad, se observa que a partir de los ca. $200 \mathrm{~m}$ los artefactos son escasos (Figura 3B). El artefacto registrado a mayor distancia de la laguna fue recolectado a $300 \mathrm{~m}$ hacia el noreste.

\section{La tecnología lítica}

Con respecto al material lítico recuperado en LL4, se analizaron los artefactos de las seis transectas $(\mathrm{n}=1.841)$. Se identificaron 20 materias primas cuyos rodados muy probablemente provienen de depósitos localizados en las márgenes del Río Negro (Bonomo y Prates 2014; Mange 2019; Prates 2008), a ca. $30 \mathrm{~km}$ del sitio. Predominan las rocas silíceas $(45,63 \%)$, seguidas por el basalto/andesita $(19,50 \%)$

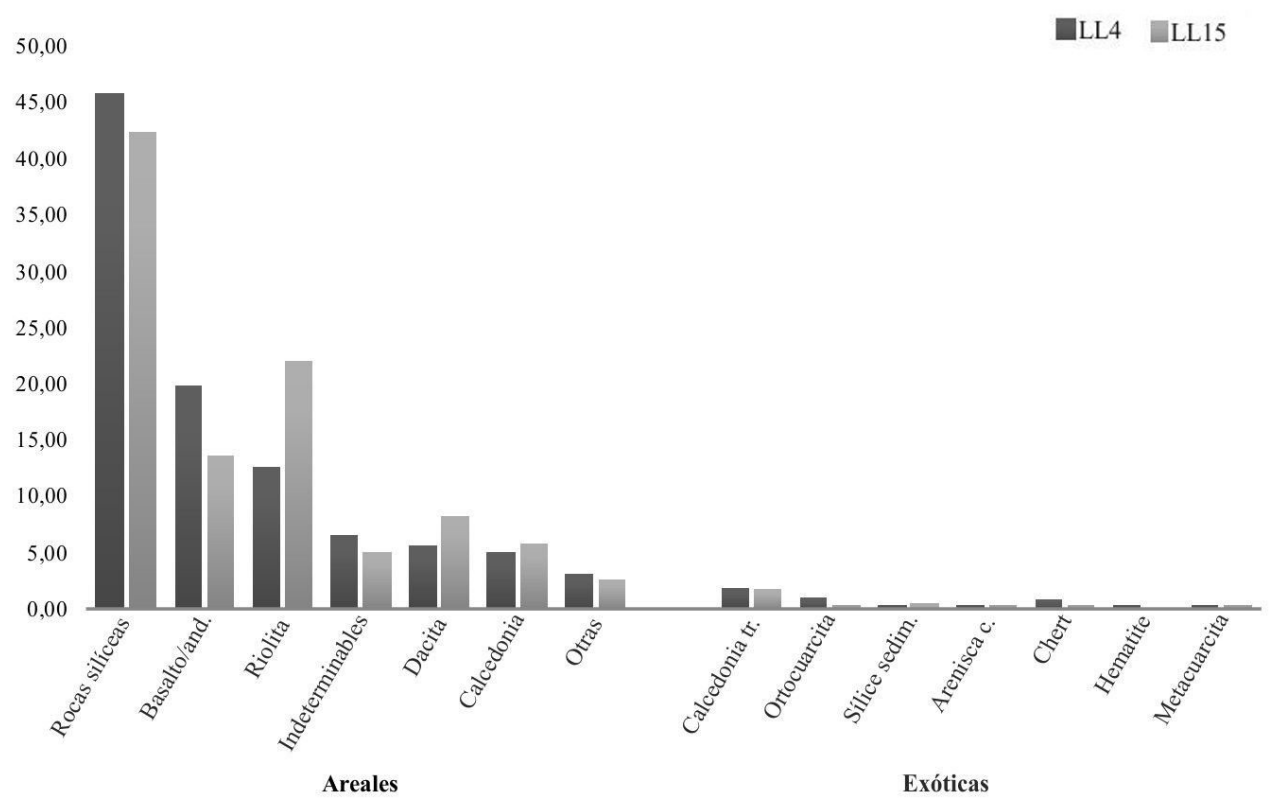

Figura 5. Materias primas representadas en los conjuntos artefactuales analizados de LL4 y LL15. Referencias: Basalto/and.: Basalto/andesita; Calcedonita tr.: Calcedonia translúcida; Sílice sedim.: Sílice sedimentario; Arenisca c.: Arenisca cuarzosa.

Raw materials represented in the artifact assemblages analyzed for LL4 and LL15. References: Basalto/and.: Basalt/ andesite; Calcedonia tr.: Translucent chalcedony; Sílice sedim.: Sedimentary silex; Arenisca c.: Quartz sandstones. 
y la riolita $(12,33 \%)$. En porcentajes menores al $2 \%$ fueron registradas rocas exóticas como la calcedonia translúcida, ortocuarcita, la arenisca cuarzosa, el chert, el sílice sedimentario y el hematite (Figura 5).

En líneas generales se observa que la categoría más frecuente en todas las transectas es la de los desechos de talla, seguidos en proporción por los instrumentos (Tabla 1). Dentro de la categoría de desechos de talla, son a su vez las lascas y microlascas las que presentan

Tabla 1. Cantidades y frecuencias de las categorías artefactuales representadas en cada conjunto. Referencias: D. térmicos: Desprendimientos térmicos.

Quantities and frequencies of the artifact categories represented in each assemblage. References: D. térmicos: Pot-lid fracture spalls.

\begin{tabular}{ccccc}
\hline & \multicolumn{2}{c}{ LL4 } & \multicolumn{2}{c}{ LL15 } \\
\hline & $\mathrm{N}$ & $\%$ & $\mathrm{~N}$ & $\%$ \\
\hline Desechos talla & 1520 & 82,6 & 1451 & 75,2 \\
\hline Ecofactos & 27 & 1,5 & 13 & 0,7 \\
\hline Instrumentos & 207 & 11,2 & 263 & 13,6 \\
\hline Núcleos & 71 & 3,9 & 190 & 9,8 \\
\hline D. térmicos & 12 & 0,7 & 12 & 0,6 \\
\hline Pièces esquillées & 4 & 0,2 & $/$ & $/$ \\
\hline Total & 1841 & 100 & 1929 & 100 \\
\hline & & & &
\end{tabular}

las mayores frecuencias $(\mathrm{n}=1.478 ; 80,28 \%)$, con una muy baja representación de desechos indeterminables $(\mathrm{n}=42 ; 2,28 \%)$. El análisis de las primeras indica que se trata en general de artefactos de tamaños medianopequeños $(23,41 \%)$, pequeños $(21,92 \%)$ y módulos espesos $(53,92 \%)$. Las lascas mejor representadas son las indeterminables $(39,78 \%)$, angulares $(19,55 \%)$ y de dorso natural $(10,69 \%)$. Sumado a ello, se registraron cinco lascas $(0,34 \%)$ de reactivación de plataformas de núcleos. La mayoría de las lascas no posee corteza en su cara dorsal $(54,53 \%)$, seguidas en frecuencia por aquellas en las que la corteza no supera el $50 \%(27,74 \%)$.

Con respecto a los instrumentos $(n=207)$, se identificaron 22 grupos tipológicos (Tabla 2), entre los que se destacan las lascas con rastros complementarios $(35,27 \%)$, los instrumentos compuestos $(20,29 \%)$ y los raspadores $(14,49 \%)$. En líneas generales son artefactos de tamaños mediano-pequeños $(27,57 \%)$ y medianograndes $(15,94 \%)$, de módulos mayoritariamente espesos $(52,56 \%)$. Es necesario destacar que dentro
Tabla 2. Grupos tipológicos representados en LL4 y LL15. Referencias: Fg. Bola de boleadora: Fragmento de bola de boleadora; Inst. de molienda indet.: Instrumento de molienda indeterminable.

Typological categories represented at LLA and LL15. References: Fg. Bola de boleadora: Bola fragment; Inst. de molienda indet.: Undetermined grinding stone.

\begin{tabular}{lcccc}
\hline \multirow{2}{*}{ Grupo tipológico } & \multicolumn{2}{c}{ LL4 } & \multicolumn{2}{c}{ LL15 } \\
\cline { 2 - 5 } & $\mathrm{N}$ & $\%$ & $\mathrm{~N}$ & $\%$ \\
\hline Lasca rastros complementarios & 73 & 35,27 & 54 & 20,53 \\
\hline Instrumento compuesto & 42 & 20,29 & 58 & 22,05 \\
\hline Raspador & 30 & 14,49 & 45 & 17,11 \\
\hline Filo en bisel asimétrico unifacial & 15 & 7,25 & 23 & 8,75 \\
\hline Lasca retoque sumario & 8 & 3,86 & 9 & 3,42 \\
\hline Punta de proyectil & 5 & 2,42 & 8 & 3,04 \\
\hline Instrumento indeterminable & 5 & 2,42 & 7 & 2,66 \\
\hline Muesca & 5 & 2,42 & 4 & 1,52 \\
\hline Esbozos bifaciales & 4 & 1,93 & 10 & 3,8 \\
\hline Percutor & 3 & 1,45 & 16 & 6,08 \\
\hline Preforma punta & 3 & 1,45 & 4 & 1,52 \\
\hline Filo festoneado & 2 & 0,97 & 1 & 0,38 \\
\hline Raclette & 2 & 0,97 & 1 & 0,38 \\
\hline Yunque & 2 & 0,97 & 1 & 0,38 \\
\hline Denticulado & 1 & 0,48 & 1 & 0,38 \\
\hline Fg. Bola de boleadora & 1 & 0,48 & 3 & 1,14 \\
\hline Filo bifacial & 1 & 0,48 & 2 & 0,76 \\
\hline Inst. de molienda indet. & 1 & 0,48 & 6 & 2,28 \\
\hline Molino & $/$ & 0 & 1 & 0,38 \\
\hline Punta destacada & 1 & 0,48 & 7 & 2,66 \\
\hline Perforador & 1 & 0,48 & $/$ & 0 \\
\hline Pieza con bordes machacados & 1 & 0,48 & $/$ & 0 \\
\hline Plaqueta con retoque sumario & 1 & 0,48 & $/$ & 0 \\
\hline Filo de raedera & $/$ & 0 & 2 & 0,76 \\
\hline & 207 & 100 & 263 & 100 \\
\hline & & & & \\
\hline
\end{tabular}

del conjunto se recuperaron cinco puntas de proyectil $\mathrm{y}$ tres preformas de puntas, todas ellas apedunculadas. Estos instrumentos fueron realizados preferentemente sobre rocas silíceas $(n=5)$, registrándose en menor medida piezas sobre basalto/andesita $(\mathrm{n}=2)$ y calcedonia $(\mathrm{n}=1)$. Mientras que las puntas de proyectil son pequeñas y mediano-pequeñas ( $\mathrm{n}=2$ en cada caso; solo en una pieza no pudo estimarse el tamaño), las preformas se caracterizan por poseer diferentes tamaños: grande, mediano-grande y mediano-pequeño ( $\mathrm{n}=1$ en cada caso).

Los núcleos $(\mathrm{n}=71)$ fueron desarrollados en todos los casos sobre rodados y sirvieron para la extracción de lascas. Se caracterizan por ser mayoritariamente mediano pequeños $(29,58 \%)$, grandes y mediano grandes $(19,72 \%$ en cada caso). Once $(15,49 \%)$ núcleos se encuentran agotados y en cuatro $(5,36 \%)$ se evidenció la rotación de los frentes de extracción durante la talla. También se recuperaron ecofactos $(\mathrm{n}=27)$, desprendimientos térmicos $(\mathrm{n}=12)$ y cuatro pièces esquillées ${ }^{2}$ (Tabla 1). Con respecto a estas 
últimas, es destacable que tres de ellas se desarrollaron sobre materias primas exóticas (dos de chert y una de calcedonia translúcida).

En lo que respecta a LL15, se consideraron los materiales recuperados en las ocho transectas $(\mathrm{n}=1.929)$. Al igual que en LL4, se observa una explotación preferencial de rocas locales entre las que predominan las silíceas $(42,20 \%)$ seguidas por la riolita $(21,77 \%)$ y basalto/andesita (13,32\%) (Figura 5), muy probablemente obtenidas a ca. $20 \mathrm{~km}$ del sitio, en las márgenes del Río Negro. En porcentajes que no superan el $1,5 \%$ se registraron rocas exóticas como las calcedonias translúcidas, sílice sedimentario, areniscas cuarzosas, metacuarcita, ortocuarcita y cherts. La categoría artefactual mejor representada corresponde a los desechos de talla, seguidos por instrumentos y núcleos (Tabla 1). En lo que respecta a los primeros, las lascas y microlascas comprenden el 93,9\% ( $\mathrm{n}=1.362)$ de este conjunto, mientras que el $6,1 \%(n=89)$ restante lo integran los desechos indeterminables. El análisis de las lascas y microlascas indica que se trata mayoritariamente de artefactos mediano-pequeños $(32,09 \%)$ y espesos $(53,38 \%)$. Los tipos de lascas mejor representados son las indeterminables $(36,64 \%)$, de dorso natural $(13,66 \%)$ y primarias $(12,85 \%)$. Se destaca la presencia de nueve $(0,66 \%)$ lascas de reactivación de plataformas de núcleos. Más de la mitad (52,64\%) de estos desechos no poseen corteza en su cara dorsal, seguidos por aquellos con menos del $50 \%$ de su cara dorsal cubierta $(22,32 \%)$.

Entre los instrumentos $(n=263)$ se identificaron 21 grupos tipológicos, en los que los instrumentos compuestos $(22,05 \%)$, las lascas con rastros complementarios $(20,53 \%)$ y raspadores $(17,11 \%)$ son los predominantes (Figura 6, Tabla 2). Si bien se observa una gran variabilidad de tamaños que van desde pequeños $(6,08 \%)$ a muy grandes $(3,42 \%)$, aquellos de tamaños mediano-pequeños $(26,24 \%)$ y mediano-grandes $(20,91 \%)$, y de módulos de anchura/ espesor espesos $(50,95 \%)$, son los más frecuentes. Se registraron ocho puntas de proyectil y cuatro preformas, todas apedunculadas (Figura 6). Estos instrumentos fueron confeccionados sobre rocas silíceas, cherts y calcedonias (solo una preforma fue realizada sobre basalto/andesita) y presentan tamaños pequeños y mediano-pequeños.

Los núcleos ( $\mathrm{n}=190)$, son en todos los casos el resultado de la talla de rodados para la extracción de lascas. Entre los tamaños predominan los mediano grandes $(27,89 \%)$ y grandes $(25,79 \%)$. El $20,53 \%$ se encuentran agotados, mientras que el $6,84 \%$ presentan evidencias de haber sido rotados durante el proceso de

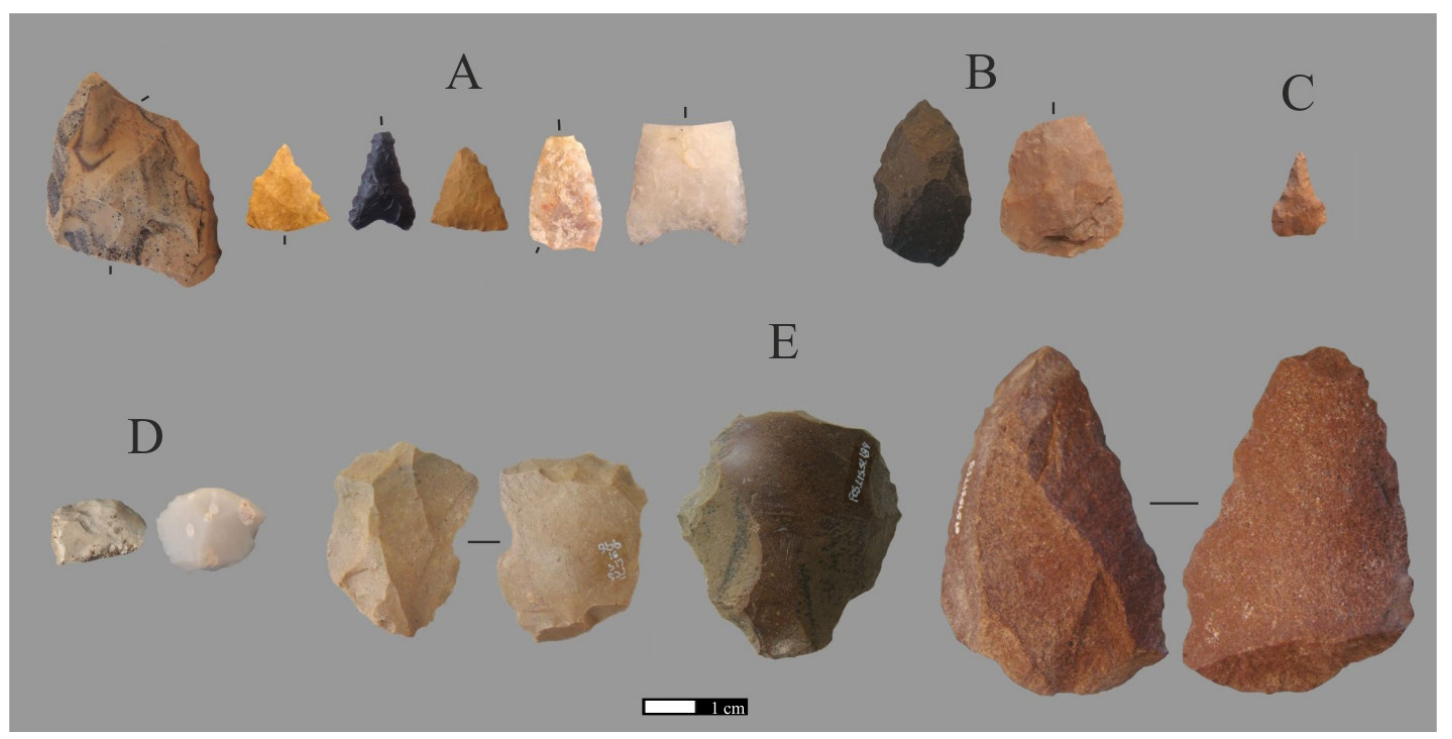

Figura 6. Instrumentos recuperados en LL4 y LL15. (A) Puntas de proyectil; (B) preformas de puntas de proyectil; (C) perforador sobre punta de proyectil; (D) raspadores y (E) instrumentos compuestos.

Tools recovered from LL4 and LL15. (A) Projectile points; (B) Projectile point preforms; (C) Drill on projectile point; (D) Scrapers and $(E)$ Composed tools. 
talla. Finalmente es necesario destacar la presencia de ecofactos $(n=13)$ y desprendimientos térmicos $(n=12$; Tabla 1).

Debido a que no se observan diferencias significativas en cuanto a la gestión de rocas en los conjuntos de ambos lotes, las tendencias resultantes del análisis tecnológico de cada uno se expondrán de manera conjunta. En ambos casos, el análisis llevado a cabo indica la producción de instrumentos a partir de la talla de rodados. La selección de rocas se orientó a nódulos de tamaños medianos-grandes y grandes, tanto de morfologías ovaladas como con aristas, entre las que se destacan las triangulares. La producción de soportes se realizó casi exclusivamente de manera unipolar corta (Figura 7) y centrípeta (Figura 8), a partir de la percusión dura (talones lisos, lisos naturales y corticales, espesos y de bulbos pronunciados, entre otros rasgos). La percusión directa blanda (talones puntiformes, filiformes, diedros o facetados, poco espesos, con presencia de labio y bulbos difusos, entre otros rasgos) se observó en etapas avanzadas de la producción de soportes, así como de la confección de algunos instrumentos. De esta manera se generaron soportes diferenciados, de morfologías alargadas en el primer caso (Figura 7) y anchas, cortas y de bordes redondeados en el segundo (Figura 8). Los soportes generados en las primeras etapas de producción a partir de la implementación de ambos métodos habrían servido para la confección de instrumentos compuestos, esbozos y raspadores, por medio de retoques marginales y microrretoques ultramarginales (Figuras 7 y 8). Aquellos soportes resultantes de las etapas más avanzadas fueron empleados para la confección de raspadores, muescas, lascas con retoques sumarios, instrumentos compuestos y filos en bisel asimétrico unifacial ${ }^{3}$, mediante retoques y microrretoques marginales (Figuras 7 y 8 ).

Como se observa en las Figuras 7 y 8 , también se emplearon los filos naturales de las lascas generadas

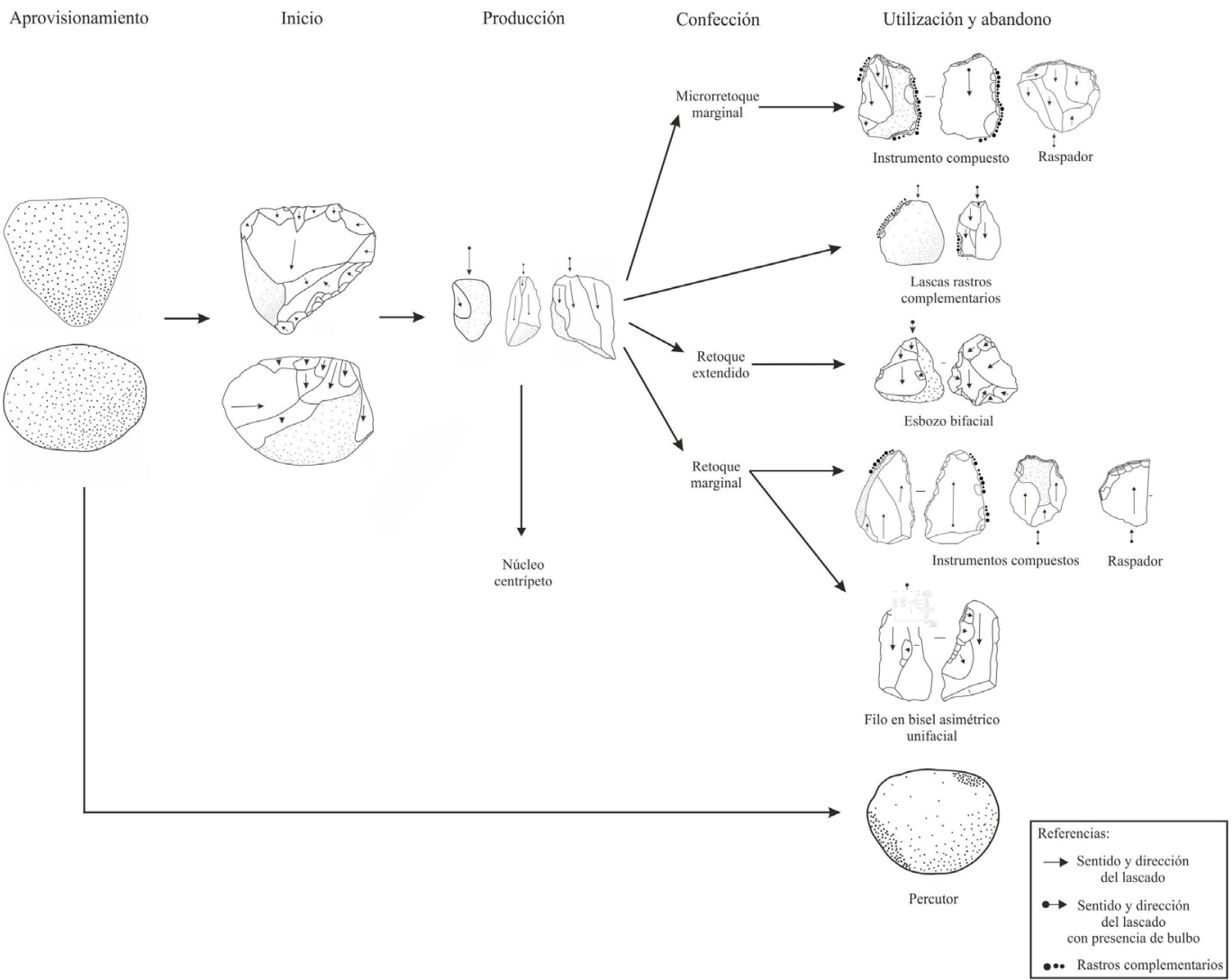

Figura 7. Cadena operativa de producción de las rocas mayoritarias. Método de débitage unipolar corto.

Chaîne opératoire built according to the best-represented rocks. Unipolar débitage method. 


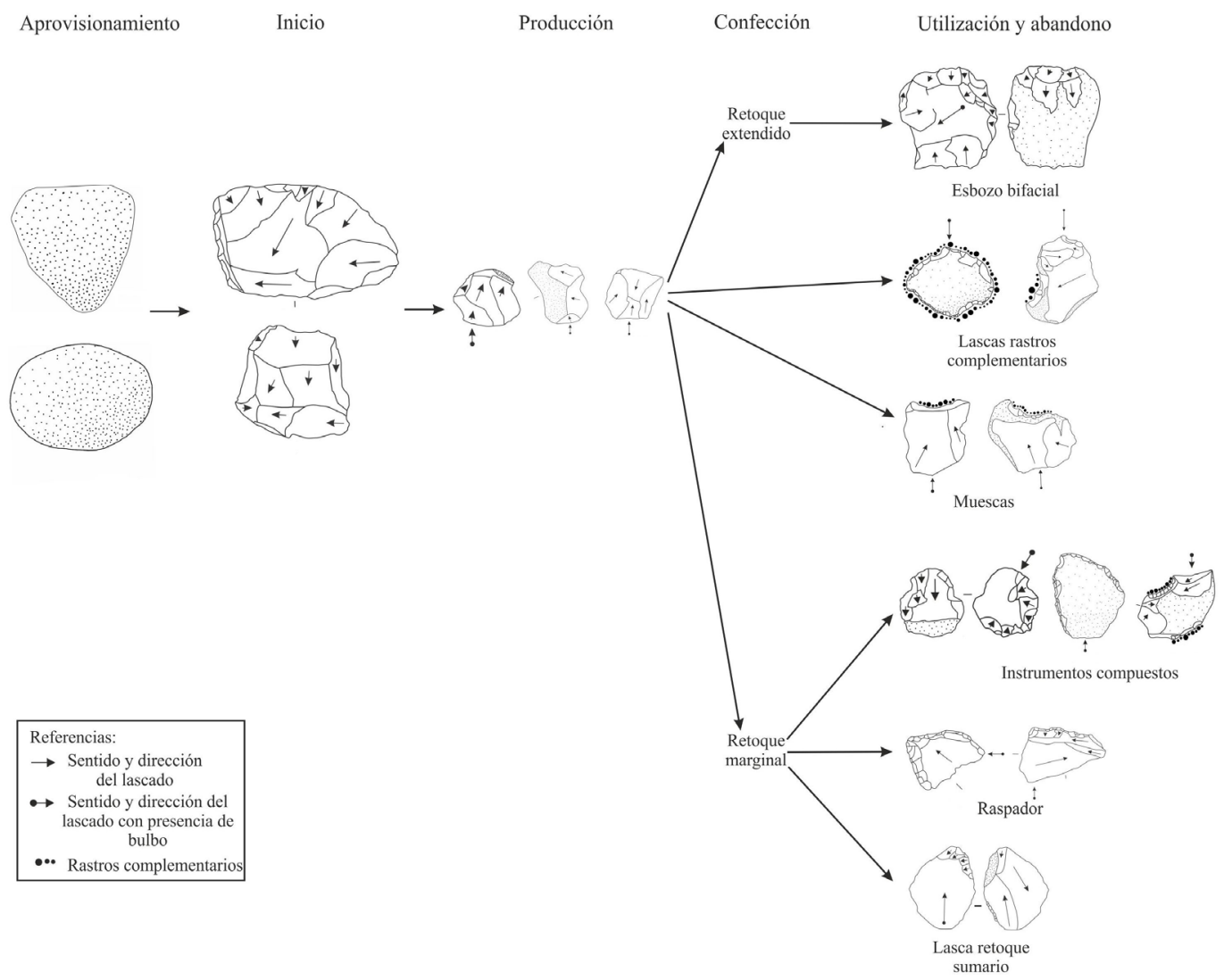

Figura 8. Cadena operativa de producción de las rocas mayoritarias. Método de débitage centrípeto.

Chaîne opératoire built according to the best-represented rocks. Centripetal débitage method.

a lo largo de todas estas etapas. En el caso de los raspadores y filos en bisel asimétrico unifacial, se eligieron preferentemente lascas de rocas silíceas, muy espesas y medianas. Para los instrumentos compuestos se seleccionó una mayor variabilidad de soportes, lo que podría responder a la variedad de grupos tipológicos que este conjunto engloba (p.ej., frentes de raspador, puntas destacadas, muescas, filos de raedera, filos en bisel asimétrico unifacial, etc.).

En muy baja frecuencia se registró el uso del débitage bipolar, tanto para la talla de rodados de dimensiones menores a $4 \mathrm{~cm}$ como para la optimización de núcleos resultantes de la aplicación de otros métodos. Esta tendencia a maximizar las materias primas se observó también en el cambio de plataformas de extracción de un mismo núcleo a lo largo de la talla. Esto involucró, en algunos casos, cambios en los métodos de débitage empleados durante este proceso, en función de la modificación de la morfología del núcleo y los ángulos de las plataformas, resultando en el agotamiento de algunos de los artefactos. En mucha menor proporción se registró el façonnage sobre plaquetas, que permitió la confección de esbozos a partir de la reducción de estos soportes mediante la talla y el retoque bifacial. El trabajo bifacial se observó también sobre lascas de diferentes espesores cuyos métodos de obtención no pudieron determinarse. En este sentido, se registró la reducción de lascas espesas a muy espesas, mayores a $5 \mathrm{~cm}$ de longitud, a partir de la talla y el retoque bifacial, para la producción de esbozos y puntas de proyectil. Sobre este mismo tipo de soportes (lascas espesas-muy espesas) se observaron tareas de reducción unifacial para la confección de instrumentos compuestos y filos en bisel asimétrico unifacial, así como de operaciones de reducción y adelgazamiento unifacial por retoques para la manufactura de raspadores y esbozos bifaciales. Finalmente, se registró el adelgazamiento bifacial por retoques y microrretoques de lascas espesas a poco 
espesas, menores a $5 \mathrm{~cm}$ de longitud, para la confección de puntas de proyectil e instrumentos compuestos.

En lo que respecta a las rocas exóticas, se identificaron ortocuarcitas de Tandilia (ca. $550 \mathrm{~km}$ de los sitios), arenisca cuarzosa y metacuarcita de las sierras de Ventania (ca. $300 \mathrm{~km}$ ), sílices sedimentarios del área de Bajos sin Salida (ca. 120 km), cherts que posiblemente provengan de la Meseta del Fresco y/o Laguna El Carancho (ca. $350 \mathrm{~km}$ ) y calcedonia translúcida, cuyas fuentes podrían localizarse en el Golfo San Matías (ca. 130 km) y/o en la Meseta de Somuncurá (ca. $300 \mathrm{~km}$ ). Todas estas rocas se encuentran representadas mayoritariamente como lascas de etapas avanzadas de producción e instrumentos, a excepción de la calcedonia translúcida y el chert. Con respecto a la calcedonia translúcida, si bien no se registraron ecofactos o núcleos, se encuentran presentes lascas primarias y avanzadas, producto de la implementación de los métodos de talla unipolar y centrípeto. Estos desechos habrían servido como formas base para la confección de raspadores y puntas de proyectil. Se observó también la presencia de una muesca sobre una lasca de limpieza de núcleo, un instrumento confeccionado a partir del retoque marginal de los bordes de una plaqueta y lascas resultantes de etapas de formatización. En lo que respecta al chert, se registró la presencia de núcleos agotados, desechos de etapas avanzadas, una punta de proyectil, un raspador, un instrumento compuesto y un instrumento indeterminable.

\section{El registro estratificado}

\section{Aspectos estratigráficos. Resolución e integridad}

Tal como fue anteriormente mencionado, en cada caso de estudio se realizaron cinco sondeos estratigráficos en diferentes sectores ligados a los
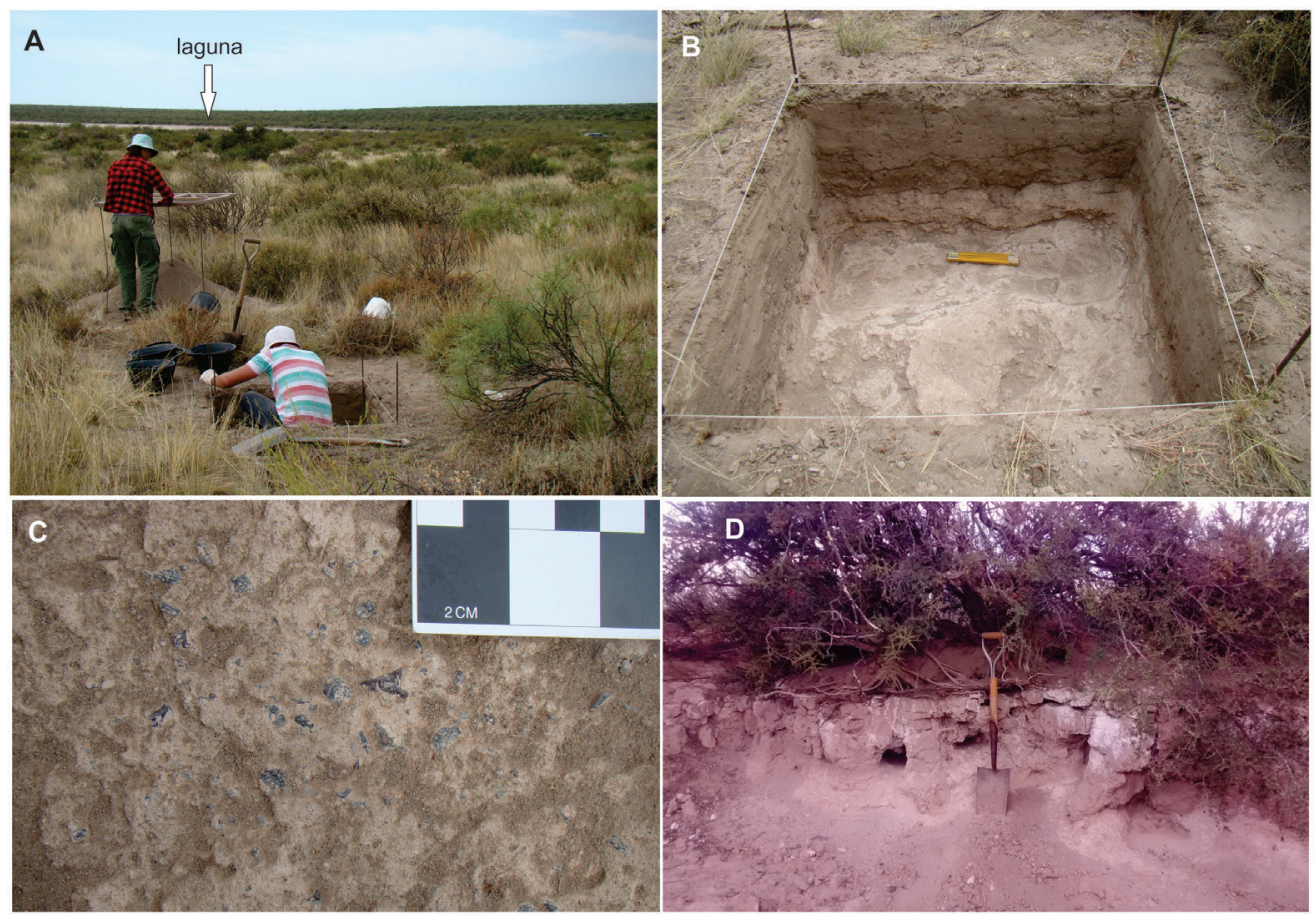

Figura 9. (A) Sondeo 1 en el lado norte de LL4; (B) Estratigrafía del Sondeo 1 donde se observan depósitos lagunares en la base de la columna, en discordancia con los mantos eólicos superiores; (C) Detalle de los sedimentos lagunares basales compuestos por sustratos duros, entoscados, con clastos tamaño sábulo y gravas; (D) Corte Natural ubicado en el sector oeste de LL4. Se observa la Formación Río Negro en la base en franca discordancia con eólicos superiores modernos.

(A) Test pit 1 on the northern side of LLA; (B) Stratigraphy of test pit 1 where lagoon deposits were recorded at the base of the stratigraphic column, inconsistent with aeolian layers in the upper section; $(C)$ Detail of the lagoon basal sediments made up of hard, cemented substrates, with embedded granules and pebbles; (D) Natural section located in the western sector of LL4. The Río Negro Formation can be seen at the base, clearly inconsistent with modern upper aeolian deposits. 
Tabla 3. Información sobre textura y otros parámetros obtenidos de muestras sedimentarias de sondeos de LL4. Referencias: H: Humedad; O: Orgánicos; C: Carbonatos; R.S.: Residuos silíceos.

Information on texture and other parameters obtained from sediment samples from LL4 test pits. References: H: Humidity; O: Organic; C: Carbonates; R.S.: Siliceous residues.

\begin{tabular}{|c|c|c|c|c|c|c|c|c|c|c|c|c|c|c|c|c|c|}
\hline \multirow{2}{*}{$\begin{array}{c}\text { Procedencia/ } \\
\text { Muestra }\end{array}$} & \multirow[t]{2}{*}{ Tratamiento } & \multicolumn{11}{|c|}{ Clasificación Udden - tamaños en um } & \multirow{2}{*}{$\begin{array}{l}\% \\
\mathrm{H}\end{array}$} & \multirow{2}{*}{$\begin{array}{l}\% \\
\mathrm{O}\end{array}$} & \multirow{2}{*}{$\begin{array}{l}\% \\
\mathrm{C}\end{array}$} & \multirow{2}{*}{$\begin{array}{c}\% \\
\text { R.S. }\end{array}$} & \multirow{2}{*}{$\mathrm{pH}$} \\
\hline & & 0,1 & 2 & 3,9 & 7,8 & 15,6 & 31,2 & 63 & 125 & 250 & 500 & 1000 & & & & & \\
\hline $\begin{array}{c}\text { Lote 4. Sitio } \\
\text { 1. Sondeo } 2 . \\
45 \mathrm{~cm}\end{array}$ & Químico & & 10,97 & 5,76 & 5,00 & 5,37 & 8,69 & 14,43 & 12,33 & 12,55 & 18,95 & 5,95 & 4,26 & 2,02 & 1,78 & 96,23 & 7,40 \\
\hline \multirow[t]{3}{*}{$\begin{array}{c}\text { Lote 4. Sitio } \\
\text { 1. Sondeo } 4 . \\
55 \mathrm{~cm}\end{array}$} & Químico & & 6,95 & 4,72 & 5,91 & 6,80 & 10,78 & 17,98 & 15,81 & 13,55 & 14,98 & 2,52 & 3,47 & 2,88 & 13,52 & 84,26 & 8,70 \\
\hline & & & & & $\begin{array}{l}\text { muy } \\
\text { fino }\end{array}$ & fino & medio & grueso & $\begin{array}{l}\text { muy } \\
\text { fina }\end{array}$ & fina & media & gruesa & & & & & \\
\hline & & & \multicolumn{2}{|c|}{ arcilla } & & \multicolumn{2}{|c|}{ limo } & & & \multicolumn{2}{|c|}{ arena } & & & & & & \\
\hline
\end{tabular}

cuerpos lagunares (Figuras 3 y 9). De esta forma, a los resultados de los análisis distribucionales, se buscó sumar información estratigráfica para comprender más acabadamente la geomorfología y la estructura del registro arqueológico, su resolución e integridad. Por motivos de espacio, y teniendo en cuenta que las características estratigráficas de los sondeos son similares, se describirán los que ofrecen resultados más relevantes para la discusión de estos tópicos.

El sondeo 1 realizado en la LL4 (Figura 9A), se localiza a ca. $300 \mathrm{~m}$ al norte del cuerpo lagunar. $\mathrm{La}$ estratigrafía (potencia ca. $0,60 \mathrm{~m}$ ) está compuesta por cuatro unidades arenosas ubicadas en discordancia con las areniscas de la Formación Río Negro. En el sondeo 2 (potencia ca. $0,50 \mathrm{~m}$ ), localizado a ca. $60 \mathrm{~m}$ del anterior en dirección a la laguna, se reconocieron cuatro niveles arenosos (Figura 9), pero el basal es un sustrato duro, entoscado y con clastos tamaño sábulo y grava chica de vulcanitas, probablemente de origen coluvial-aluvial (Figura 9C). Esta unidad se habría comportado como parte del bajo, receptor de sedimentos lagunares.

A los efectos de verificar si se trató de un fondo de laguna se analizaron muestras de mano obtenidas de la superficie actual de la laguna y de la unidad inferior de este sondeo. En ambos casos, el sedimento es de color castaño muy pálido (10YR 8/2) (Munsell Colour Chart 1954), textura areno-limo-arcillosa (Tabla 3), con estratificación planar grosera, compacta, con bioturbaciones medias comunes a abundantes, con poros medios a grandes comunes y una fuerte reacción al HCL. Los resultados indican que el lugar donde se realizó el sondeo 2 estuvo ocupado, en algún momento en el pasado, por el cuerpo lagunar. Esta misma situación se produce en el sondeo 4 (potencia ca. $0,55 \mathrm{~m}$ ), ubicado a ca. $20 \mathrm{~m}$ al sudoeste del borde de la laguna (Figura 3A). Se observaron cuatro unidades superiores arenosas y la basal areno-limo-arcillosa. En este caso también las muestras de mano del fondo de la laguna actual y los análisis sedimentológicos de la unidad basal son consistentes entre sí (Tabla 3).

En el caso de la LL15 se describen dos sondeos. En el sondeo 1 (potencia 1,20 m), localizado a ca. $200 \mathrm{~m}$ al este de la laguna (Figura 3B), se observan en las unidades superiores depósitos eólicos (cuatro unidades) con estratificación cruzada y hacia la base, en discordancia, sedimentos lagunares. Por su parte en el sondeo 2 (potencia $0,80 \mathrm{~m}$ ), ubicado a ca. $230 \mathrm{~m}$ al este de la laguna, se observan cinco unidades estratigráficas eólicas superiores fuertemente impactadas por una paleocueva y, luego de una discordancia, sedimentos lagunares.

En síntesis, las secciones superiores de las estratigrafías están representadas por depósitos eólicos puros, donde se reconoce estratificación planar y/o entrecruzada, según los casos. Los depósitos eólicos contienen el material arqueológico (ver debajo). Las discordancias observadas entre los sedimentos eólicos y, a su vez, entre estos y los depósitos lagunares indican un ambiente con pulsos sedimentarios, con procesos de erosión-depositación. También se observaron importantes discordancias entre los sedimentos eólicos y las areniscas de la Formación Río Negro. Esto no solo fue observado en los sondeos, sino también en cortes estratigráficos naturales (Figura 9D). Los análisis de las muestras del fondo de la laguna actual, así como los de las unidades basales de algunos sondeos (p.ej., sondeos 2 y 4 de 
Tabla 4. Análisis faunísticos. Categorías taxonómicas, NISP y NMI. Nota: entre paréntesis se indica el número de placas de armadillos. N/A: no aplica.

Faunal analysis. Taxonomic categories, NISP and MNI. Note: The number of armadillo plates is indicated in brackets. N/A: not applicable.

\begin{tabular}{|c|c|c|c|c|}
\hline \multirow{2}{*}{ Categoría taxonómica } & \multicolumn{2}{|c|}{ LL4 } & \multicolumn{2}{|c|}{ LL15 } \\
\hline & NISP & NMI & NISP & NMI \\
\hline Ave mediana & 1 & 1 & 1 & 1 \\
\hline Mammalia indet. & 50 & N/A & 21 & N/A \\
\hline Artiodáctila & & N/A & 1 & N/A \\
\hline Lama guanicoe & 1 & 1 & 2 & 1 \\
\hline Ovis aries & & & 11 & 1 \\
\hline Mesomamífero & 1 & N/A & 3 & N/A \\
\hline Chlamyphoridae & $3(154)$ & N/A & $2(57)$ & N/A \\
\hline Zaedyus pichiy & $3(77)$ & 1 & $10(39)$ & 1 \\
\hline Chaetophractus villosus & (5) & 1 & (1) & 1 \\
\hline Rodentia & 1 & N/A & & \\
\hline Caviidae & 2 & N/A & & \\
\hline Dolichotis patagonum & & & 1 & 1 \\
\hline Microcavia australis & & & 1 & 1 \\
\hline Cricetidae & & & 1 & 1 \\
\hline Ctenomys sp. & 3 & 1 & & \\
\hline Total sin placas & 65 & 5 & 54 & 8 \\
\hline Total con placas & 301 & & 151 & \\
\hline
\end{tabular}

LL4), tienen características sedimentológicas muy similares. Esto implica que a pesar de que el borde de la laguna ha tenido variaciones espaciales (lo que también es apoyado por las imágenes satelitales), el ambiente sedimentario se ha mantenido constante desde el inicio de los bajos hasta su dinámica actual. Los bajos han receptado en su parte más profunda los sedimentos más finos llevados por escorrentía, conjuntamente con sales disueltas, donde domina el $\mathrm{CaCO}_{3}$.

\section{La cultura material recuperada de las excavaciones}

En estos sondeos se recuperaron distintos materiales. Para la LL4, casi la totalidad de los artefactos líticos recuperados en los sondeos $(\mathrm{n}=326)$ son desechos de talla $(96,6 \%)$, seguidos por núcleos, instrumentos $(1,2 \%$ en cada caso) y ecofactos $(0,9 \%)$. Las rocas silíceas, riolitas y rocas indeterminadas son las materias primas más representadas. Se recuperó un total de 791 restos faunísticos, los cuales provienen principalmente de los sondeos $4(n=460)$ y $5(n=312)$. La mayor frecuencia de restos corresponde a fragmentos indeterminados (ca. $62 \% ; n=490$ ), que poseen tamaños inferiores a $1 \mathrm{~cm}$. Debido al elevado grado de fragmentación que presenta el conjunto, escasos especímenes pudieron ser atribuidos a categorías taxonómicas específicas como armadillos, roedores y guanaco (Tabla 4). Ninguno de los restos recuperados posee modificaciones que puedan ser atribuidas a la actividad antrópica. Además, se recuperaron fragmentos de cáscara de huevo de Rheidae $(n=1.053)$, de carbón $(n=3)$, de valva $(\mathrm{n}=6)$ y una cuenta.

En la LL4 se recuperaron seis tiestos de los sondeos 4 y 5 . Los mismos pertenecen al sector del cuerpo de las vasijas y se encuentran altamente fragmentados, no superando en ningún caso los $25,5 \mathrm{~mm}$ de largo y $20 \mathrm{~mm}$ de ancho. Dichos fragmentos presentan espesores de entre 4 y $6 \mathrm{~mm}$, superficies externas pulidas e internas alisadas. En dos casos la superficie externa está decorada con incisiones lineales de trazo corto. Asimismo, se registró el predominio de la oxidación incompleta de las piezas.

Respecto de la LL15, los análisis líticos muestran la misma representación de las rocas que en el lote anterior. Los materiales líticos recuperados $(n=345)$ son también predominantemente desechos de talla $(99,1 \%)$, seguidos por núcleos $(0,9 \%)$. Se recuperaron 531 restos óseos que provienen en su mayoría del sondeo $2(\mathrm{n}=502)$. De estos, el ca. $72 \%(\mathrm{n}=380)$ corresponde a fragmentos indeterminados de tamaño menor a $1 \mathrm{~cm}$. Entre los escasos restos que pudieron ser identificados con algún grado de especificidad taxonómica predominan los correspondientes a Mammalia indet., Ovis aries y Zaedyus pichiy (Tabla 4). En este caso, tampoco se pudieron observar modificaciones que indiquen acción antrópica sobre los taxa representados. Se registraron también fragmentos de cáscaras de huevo de Rheidae $(n=8)$, de carbón $(n=3)$, de vidrio y metal (uno en cada caso). Se recuperaron tres tiestos procedentes de los sondeos 1 y 5 . Al igual que en el caso anterior, se corresponden con fragmentos de cuerpo que no superan los $25 \mathrm{~mm}$ de largo y $24 \mathrm{~mm}$ de ancho, a excepción de un ejemplar de mayores dimensiones (51 $\mathrm{mm}$ de largo y $41 \mathrm{~mm}$ de ancho). Las paredes poseen un espesor comprendido entre 4 y $6 \mathrm{~mm}$. Las superficies externas e internas se encuentran en todos los casos pulidas y un ejemplar, además, está decorado por una capa de colorante amarillo. Las piezas habrían sido sometidas a una atmósfera de cocción predominantemente no oxidante. 


\section{Discusión}

\section{Análisis distribucionales y uso del espacio}

La distribución y densidad artefactual alrededor de ambas lagunas no es homogénea. Las variables ambiente sedimentario, potencial de enterramiento y pendiente no presentan diferencias. Aunque en ambos casos predominó la vegetación de tipo monte y pastizales, se registraron algunas diferencias en la visibilidad. En este sentido, en el caso de LL4 predominaron las categorías regular-mala, mientras que para LL15 las condiciones de visibilidad regular-buena fueron las más frecuentes. Esta variable pudo influir en el hallazgo de materiales y su caracterización a través de los intervalos, ya que los resultados muestran que mientras algunos sectores presentan frecuencias altas de artefactos ("puntos calientes"), otros carecen de materiales. No obstante, cabe destacar que en sectores con alta densidad artefactual se registró material en intervalos con categorías de visibilidad que cubren el rango mala-muy buena. En estos casos, probablemente el factor de la visibilidad no haya jugado un rol destacado en la detección de artefactos. Por otra parte, si bien en ambos casos de estudio las transectas realizadas en los caminos presentaron condiciones de visibilidad muy buena y excelente, solo algunos sectores contaron con importantes densidades artefactuales. Este es el caso principalmente de los sectores aledaños a las lagunas, hasta ca. 150-200 m, registrándose a partir de aquí solo hallazgos aislados y/o ausencia de material. Claramente, en este caso el registro de artefactos no dependió de las condiciones de visibilidad. Considerando las dos lagunas estudiadas, las mayores densidades de materiales se encuentran en el sector oeste de LL4 mientras que esta situación fue observada en los sectores sur y este de LL15. Dado que las variables ambientales, topográficas y geomorfológicas son homogéneas entre ambas lagunas, y lo antedicho sobre la visibilidad, se sugiere que la densidad y forma de las distribuciones artefactuales son el correlato de patrones específicos de ocupación humana del espacio.

\section{Análisis lítico, obtención de materias primas y estadios de reducción}

Con respecto al análisis de los artefactos líticos, se propone que los grupos que ocuparon estos lugares se aprovisionaron directamente de rocas que se encontraban disponibles de forma segura en el curso medio del Río Negro (ca. 20 y $30 \mathrm{~km}$ de cada sitio). $\mathrm{Si}$ bien no puede descartarse el aprovisionamiento en algunos sectores del interfluvio, hasta el momento no se han observado afloramientos naturales. En ambos casos de estudio se explotaron las mismas variedades litológicas. La selección de nódulos apuntó preferentemente a aquellos rodados de rocas silíceas y riolitas, de morfologías ovaladas y triangulares y tamaños medianos, características óptimas para el desarrollo de los métodos unipolar corto y centrípeto. Considerando ambas lagunas no se registraron variaciones en las secuencias de producción sobre cada roca, lo que indica que responden a una misma norma técnica. Como resultado, se obtuvieron una gran variedad de soportes que permitieron la confección de una importante variabilidad de grupos tipológicos (Tabla 2). Este último aspecto, junto con la presencia de ecofactos mayores a $4 \mathrm{~cm}$, núcleos rotados y agotados, lascas resultantes de todas las etapas de producción y artefactos que representan estadios de producción intermedios (p.ej., esbozos y preformas), sugieren que todas las etapas de producción sobre estos rodados locales habrían sido llevadas a cabo en LL4 y LL15.

Finalmente, se registró la presencia de materias primas procedentes de Pampa Seca, Pampa Húmeda y Norpatagonia. Su baja frecuencia y la representación mayoritaria de lascas de etapas avanzadas de producción e instrumentos, indica que estos grupos tuvieron acceso a rocas procedentes de largas distancias, ya sea mediante su aprovisionamiento directo o su intercambio.

\section{Excavaciones}

Respecto de los sondeos realizados, dado el estado (muy deteriorados), origen (moderno en algunos casos) y tamaño (pequeño) de los materiales, las discordancias registradas y la falta de un patrón estratigráfico en su distribución, se concluye que la integridad y resolución de estos contextos es mala, tratándose de palimpsestos. A excepción del material lítico y cerámico, en el caso de la fauna, dado su alto estado de fragmentación y escasa posibilidad de asignarla a categorías taxonómicas específicas, no puede garantizarse en todos los casos su estatus arqueológico. Por lo tanto, no se dataron especímenes $\mathrm{y}$, en consecuencia, no se dispone de edades absolutas. Sobre la base de las cronologías asignadas a las formaciones geológicas detectadas, los ambientes descritos se podrían vincular cronológicamente al 
Mioceno Tardío, Pleistoceno y Holoceno. Respecto de la ocupación humana, la presencia de cerámica indica una cronología de al menos ca. 2000 años AP (ver Borges Vaz et al. 2016). En cuanto a los artefactos líticos, la presencia de puntas de proyectil triangulares apedunculadas pequeñas también apuntaría a cronologías del Holoceno Tardío (Santos Valero 2017). Hasta el momento entonces las evidencias no permiten proponer ocupaciones anteriores a este lapso.

Dadas algunas características de los materiales (básicamente líticos), se sostiene que tanto los hallazgos en superficie como en estratigrafía son expresiones diferentes de las mismas dinámicas conductuales del pasado. Estas diferentes expresiones del registro en el presente son, como ya se ha explicitado, el resultado de intensos procesos de formación que afectaron a los conjuntos. En determinados tipos de sustratos más duros (p.ej., bordes inmediatos de las lagunas) los materiales difícilmente se entierran, pero en las dunas compuestas por sedimentologías arenosas y más permeables existen mayores posibilidades de incorporación al sustrato, sobre todo en aquellas zonas ("puntos calientes") que han sido reiteradamente ocupadas (redundancia específica; ver discusión debajo).

\section{Conclusiones}

A nivel mundial se han estudiado y descrito casos etnográficos y arqueológicos provenientes de ambientes desérticos, áridos-semiáridos, en los cuales el agua superficial está ausente, es escasa, está distribuida de manera muy heterogénea a través del paisaje o su grado de salinidad hace que no sea bebible. Tanto en las planicies norteamericanas, en Sudáfrica como en Australia se han elaborado síntesis, propuestas y modelos que tratan sobre las estrategias de movilidad y asentamiento que utilizan los grupos cazadores-recolectores para lidiar con la disponibilidad y acceso al agua (Gould 1991; Hercus y Clarke 1986; Meltzer 1995; Rowlands y Rowlands 1965; Silberbauer 1981; Wright et al. 2013, entre muchos otros). Estas temáticas no han estado ausentes en la subregiones Pampa Húmeda (Martínez y Gutiérrez 2019) y Pampa Seca (Berón 2016), en Norpatagonia (Borella et al. 2015; Prates y Mange 2016), en el centro-oeste del país (Heider et al. 2018), e incluso existen referencias para épocas históricas (Tapia et al. 2017). Estos trabajos ilustran algunas de las estrategias implementadas para obtener y explotar este recurso crítico, como la excavación de pozos de agua, la utilización de jagüeles, de acuíferos y de lagunas efímeras, entre otros (ver síntesis en Martínez y Gutiérrez 2019:145-146). En el caso aquí presentado, el interfluvio carece de cuerpos permanentes de agua superficial, pero las numerosas lagunas que poseen agua de manera efímera e intermitente le han impreso al área un carácter especial a la hora de su ocupación por parte de las sociedades cazadoras-recolectoras. A esto se suma el profundo y categórico contraste, en tanto elementos del paisaje (sensu Forman y Godron 1986), con los importantes valles fluviales adyacentes.

Uno de los objetivos planteados al principio de este trabajo fue evaluar si las sociedades cazadorasrecolectoras emplearon este espacio interfluvial como un área de tránsito entre valles y/o si fue utilizada de manera más sistemática y permanente. Como se adelantó en secciones anteriores, Borrero y colaboradores (2008:162) desarrollaron un modelo de uso del espacio que incluye dos componentes: asentamientos "programados" y asentamientos "al paso". Las expectativas arqueológicas para los asentamientos "programados" son: altas frecuencias de hallazgos, alta redundancia en el uso de los espacios, alta intensidad de uso de los espacios, localizaciones con base en los recursos principales y continuidad ocupacional en ciclos variables. Por su parte, para los asentamientos "al paso" se esperan bajas frecuencias de hallazgos, baja redundancia en el uso del espacio, baja intensidad de uso, localizaciones que no están necesariamente en lugares óptimos respecto de los recursos y discontinuidad ocupacional relacionada a los corredores.

Los resultados obtenidos en este trabajo pueden ser evaluados a la luz de las expectativas arqueológicas del modelo antes mencionado. En ambos casos (LL4 y LL15) se observó que, respecto a la frecuencia de hallazgos, medida en función de su densidad, predominan las categorías baja y media (ca. $85 \%$ ), seguidas por alta y muy alta (ca. 15\%). Independientemente de las variaciones en la densidad, en el caso de los bordes de LL4 y LL15, el 71,1\% (ca. $63.700 \mathrm{~m}^{2}$ ) y el $62,2 \%$ (ca. $78.200 \mathrm{~m}^{2}$ ) de la superficie, respectivamente, muestran presencia artefactual. En esta escala espacial, los resultados indican la existencia de redundancia genérica. Sin embargo, los "puntos calientes" podrían estar señalando que algunos sectores de estas lagunas fueron más intensa y repetidamente usados, sugiriendo casos de redundancia específica. En una escala espacial mayor, la del interfluvio, la convergencia en el hallazgo de las mismas materias primas exóticas provenientes de las mismas regiones 
(Pampa y Norpatagonia) y largas distancias (120 y $550 \mathrm{~km}$ ) permite proponer también una redundancia específica (p.ej., las lagunas) y, en consecuencia, un uso planificado de esta área. Naturalmente, las ocupaciones debieron estar en relación con la disponibilidad del recurso agua. Es probable que la mayor frecuencia de lluvias en primavera-verano haya alentado una continuidad ocupacional ligada a estos ciclos estacionales. Sobre esta base, si se analiza el modelo de Borrero et al. (2008) como un continuиm, aunque no puede descartarse la existencia de eventuales estrategias "al paso", el componente ligado a estrategias de asentamientos "programados" sería predominante.

Más allá de las consideraciones antes vertidas sobre el modelo discutido, puede plantearse como alternativa que bajo regímenes pluviales mayores y/o condiciones climáticas con más humedad, las lagunas hayan contado con mayor disponibilidad y estabilidad de agua. Es probable, en este caso, que las lagunas se transformaran en spots con ocupaciones más estables desde donde se produjera el uso más sistemático del interfluvio, para la realización de distintas actividades que tuvieran como centro a las mismas. Lamentablemente aún no se dispone de reconstrucciones paleoclimáticas locales para poner a prueba esta hipótesis.

Independientemente del rango cronológico en el que estos sectores fueron ocupados, que solo puede ser defendido para el Holoceno Tardío, las estrategias planificadas de ocupación del espacio se ven apoyadas por las recurrentes propiedades en la organización de la tecnología lítica: la explotación predominante de las mismas litologías de procedencia local, la selección y traslado de rodados de determinadas morfologías y tamaños, el patrón en la obtención de soportes (involucrando el empleo de los mismos métodos de talla), la presencia de una variabilidad importante de grupos tipológicos y la representación de toda la secuencia de reducción. Como se mencionó, a esto se suma la presencia de las mismas rocas exóticas en ambas lagunas provenientes de regiones aledañas. Estas características de los conjuntos líticos, sumadas al análisis de las densidades artefactuales (p.ej., "puntos calientes") indican que estos lugares habrían sido producto de reocupaciones (Ebert 1992:147). A pesar de que tanto el registro de superficie como el estratigráfico no aportaron evidencias confiables relacionadas a materiales orgánicos (p.ej., fauna) que permitan inferir algún tipo de actividad de subsistencia, los patrones registrados en la tecnología lítica (p.ej., diversidad de grupos tipológicos) sugerirían asentamientos relacionados con actividades múltiples, sobre todo si las lagunas cobraron un rol mayor respecto de su ocupación en ciclos con más disponibilidad de agua. En este sentido, aunque el número de tiestos cerámicos es bajo, su presencia cobra sentido como parte de actividades ligadas a lo culinario y su uso probable como contenedores de agua bajo estas condiciones de alta planificación y reuso del espacio. Eventualmente, en temporadas donde este recurso crítico se habría vuelto más escaso, es probable que los asentamientos respondieran a ocupaciones menos intensas, ligadas a propósitos específicos, pero siempre dentro de esquemas de visitas altamente planificadas.

En resumen, en cualquiera de los escenarios planteados, las ocupaciones en torno a las lagunas no responden a un patrón de asentamiento efímero, resultado de viajes ocasionales y/o mero tránsito. En este sentido, el uso del espacio fue el resultado de ocupaciones planificadas y redundantes, y el área del interfluvio habría formado una parte importante de los circuitos de movilidad de los cazadores recolectores en torno a ambos valles fluviales.

Agradecimientos: Los autores agradecen a Juan Bautista Belardi y a César Méndez por la gentil invitación para formar parte del simposio que organizaron en honor a Luis Borrero. Agradecemos especialmente a Juan Bautista Belardi por su aporte a la maduración de las ideas de este trabajo. Agradecemos al Lic. Ignacio Mangeres (Laboratorio de Geomorfología y Geología del Cuaternario -CADIC-CONICET) por los análisis texturales. A los cinco evaluadores de este trabajo, cuyos comentarios y sugerencias contribuyeron a mejorarlo. Las investigaciones fueron apoyadas por la UE-INCUAPA-CONICET (FACSO-UNICEN) y financiadas por un PICT (2016-840) de la ANPCYT.

\section{Referencias Citadas}

Alberti, J. y M. Cardillo 2015. Primary and secondary lithic raw material sources along the western coast of San Matías Gulf (Río Negro province, Argentina). A first approach to their spatial variability. Quaternary International 373:63-71.
Andreis, R. 1965. Petrografía y paleocorrientes de la Formación Río Negro tramo General Conesa-Boca del Río Negro). Revista del Museo de La Plata. Nueva Serie. Sección Geología 5 (36):245-310. 
Andrews, P. 1990. Owls. Caves and Fossils. The University of Chicago Press, Londres.

Armentano, G. 2012. Arqueología en el Curso Inferior del Río Colorado. Estudio Tecnológico de las Colecciones Líticas de Norpatagonia Oriental Durante el Holoceno Tardío. Departamentos de Villarino y Patagones, Provincia de Buenos Aires. Argentina. Tesis doctoral inédita, Facultad de Ciencias Sociales, Universidad Nacional del Centro de la Provincia de Buenos Aires/Université de Paris, Ouest-Nanterre, Nanterre.

Aschero, C.A. 1975. Ensayo para una clasificación morfológica de artefactos líticos. Informe al CONICET. Facultad de Filosofía y Letras, Universidad de Buenos Aires, Buenos Aires.

Aschero, C.A. 1983. Ensayo para una clasificación morfológica de artefactos líticos. Revisión. Guías de cátedra. Ergología y Tecnología. Facultad de Filosofía y Letras. Universidad de Buenos Aires, Buenos Aires.

Baxter, M.J., C.C. Beardah y R.V.S. Wright 1997. Some archaeological applications of kernel density estimates. Journal of Archaeological Science 24 (4):347-354.

Bayón, C., N. Flegenheimer, M. Valente y A. Pupio 1999. Dime cómo eres y te diré de dónde vienes: procedencia de rocas cuarcíticas en la región Pampeana. Relaciones de la Sociedad Argentina de Antropología XXIV:187-232.

Belardi, J.B. 2003. Paisajes Arqueológicos: un Estudio Comparativo de Diferentes Ambientes Patagónicos. Tesis doctoral inédita, Facultad de Filosofía y Letras, Universidad de Buenos Aires, Buenos Aires.

Belardi, J.B., F. Carballo Marina, L.A. Borrero y D. Grima 2019. Disponibilidad de campos de invernada e intensidad de uso del espacio en cuencas lacustres del sur de Patagonia (Santa Cruz). En Arqueología de la Patagonia: El Pasado en las Arenas, compilado por J. Gómez Otero, A. Svoboda y A. Banegas, pp. 251-258. Instituto de Diversidad y Evolución Austral, Puerto Madryn.

Bellelli, C., A. Guráieb y J. García 1985-1987. Propuesta para el análisis y procesamiento por computadora de desechos de talla lítica (DELCO-Desechos líticos computarizados). Arqueología Contemporánea 2 (1):36-53.

Berón, M. 2016. Dunes, hills, waterholes, and saltpeter beds: attractors for human populations in Western Pampa, Argentina. Quaternary International 422:163-173.

Binford, L.R. 1979. Organization and formation processes: looking at curated technologies. Journal of Anthropological Archaeology 35 (3):255-273.

Binford, L.R. 1981. Bones: Ancient Men and Modern Myths. Academic Press, Nueva York.

Blasi, A.M. 1991. Sedimentología de las gravas del Río Colorado, Argentina. Revista del Museo de La Plata. Nueva Serie. Sección Geología 10 (93):243-264.

Bonomo, M. y L. Prates 2014. La explotación de depósitos secundarios de rodados en el curso medio del río Negro y el litoral marítimo pampeano. En Artefactos Líticos, Movilidad y Funcionalidad de Sitios en Sudamérica. Problemas y Perspectivas, editado por P. Escola y S. Hocsman, pp. 77-92. BAR Publishing, Oxford.
Borella, F., M. Cardillo, C.M. Favier Dubois y J. Alberti 2015. Nuevas investigaciones arqueológicas entre Punta Pórfido y Punta Odriozola: implicancias para el entendimiento de la dinámica de las ocupaciones humanas en la Costa Oeste del Golfo San Matías (Río Negro). Relaciones de la Sociedad Argentina de Antropología XL (1):233-252.

Borges Vaz, E. 2017. La tecnología cerámica. En Arqueología de Cazadores Recolectores del Curso Inferior del Río Colorado (Provincia de Buenos Aires, Argentina). Aportes al Conocimiento de las Ocupaciones Humanas Pampeano Patagónicas, editado por G. Martínez, pp. 192-210. INCUAPA-CONICET, FACSOUNICEN, Olavarría.

Borges Vaz, E., G. Martínez y P. Madrid 2016. Análisis tecnomorfológicos y tendencias cronológicas del conjunto cerámico del sitio Loma Ruíz 1 (transición pampeano-patagónica oriental). Aportes para Pampa y Norpatagonia. Intersecciones en Antropología 17:269-280.

Borrazzo, K., L. L'Heureux, N. Cirigliano, M.C. Pallo, I. Ozán, L. Manzi y J. Charlin 2019. Prospecciones en el interfluvio GallegosChico (Santa Cruz, Argentina): nuevos datos arqueológicos. En Arqueología de la Patagonia: El Pasado en las Arenas, editado por J. Gómez Otero, A. Svoboda y A. Banegas, pp. 271-282. Instituto de Diversidad y Evolución Cultural, Puerto Madryn.

Borrero, L. 1988. Tafonomía regional. En De Procesos, Contextos y Otros Huesos, editado por N. Ratto y A.F. Haber, pp. 9-15. Instituto de Ciencias Antropológicas, Facultad de Filosofía y Letras, Universidad Nacional de Buenos Aires, Buenos Aires.

Borrero, L. 1989. Spatial heterogeneity in Fuego-Patagonia. En Archaeological Approaches to Cultural Identity, editado por S. Shennan, pp. 258-266. Unwin Hyman, London.

Borrero, L.A., R. Barberena, J. Charlin y P. Campan 2013. Geoarqueología y tafonomía en la cuenca de Potrok Aike. En Geoarqueología, organizado por J.C. Rubin de Rubin y R.T. Da Silva, pp. 9-22. Editora da PUC Goiás, Goiânia.

Borrero, L.A., J. Charlin, R. Barberena, F.M. Martin, K. Borrazzo y L. L'Heureux 2008. Circulación humana y modos de interacción al sur del río Santa Cruz. En Arqueología del Extremo sur del Continente Americano. Resultados de Nuevos Proyectos, coordinado por L.A. Borrero y N.V. Franco, pp. 155-174. Instituto Multidisciplinario de Historia y Ciencias Humanas, Consejo Nacional de Investigaciones Científicas y Técnicas, Buenos Aires.

Borrero, L.A., J.L Lanata y B. Ventura 1992. Distribuciones de hallazgos aislados en Piedra del Aguila. En Análisis Espacial en la Arqueología Patagónica, compilado por L.A. Borrero y J.L. Lanata, pp. 9-20. Editorial Ayllu, Buenos Aires.

Cabrera, A. 1976. Regiones fitogeográficas argentinas. En Enciclopedia Argentina de Agricultura y Jardinería, editado por W. Kugler, Vol. II, fasc. 1, pp. 1-85. Acme, Buenos Aires.

Carballo Marina, F. 2007. La Cuenca Superior del Río Santa Cruz: las Poblaciones Humanas y el Uso del Espacio. Tesis doctoral inédita, Facultad de Ciencias Naturales y Museo, Universidad Nacional de La Plata, La Plata.

Carden, N. y L. Prates 2015. Pinturas rupestres en un espacio funerario: el caso del sitio Cueva Galpón (departamento de Valcheta, Río Negro). Magallania 43 (1):1-20. 
Carrera Aizpitarte, M. 2014. Estudio de las Estrategias de Aprovisionamiento Lítico en las Áreas Curacó, Bajos sin Salida, Valles Transversales y Centro-este (provincia de La Pampa, Argentina). Tesis doctoral inédita, Facultad de Ciencias Sociales, Universidad Nacional del Centro de la Provincia de Buenos Aires, Olavarría.

Catella, L. 2014. Movilidad y Utilización del Ambiente en Poblaciones Cazadoras-Recolectoras del Sur de la Región Pampeana: la Cuenca del Arroyo Chasicó como Caso de Estudio. Tesis doctoral inédita, Facultad de Ciencias Naturales y Museo, Universidad Nacional de La Plata, La Plata.

Charlin, J., L.A. Borrero y M.C. Pallo 2011. Ocupaciones humanas en el área noroccidental del río Gallegos (prov. Santa Cruz, Argentina). En Bosques, Montañas y Cazadores. Investigaciones Arqueológicas en la Patagonia Meridional, compilado por L.A. Borrero y K. Borrazzo, pp. 179-210. Instituto Multidisciplinario de Historia y Ciencias Humanas, Consejo Nacional de Investigaciones Científicas y Técnicas, Buenos Aires.

Cortelezzi, C., F. De Francesco y O. de Salvo 1968. Estudio de las Gravas Tehuelches en la región comprendida entre el Río Negro y el Río Colorado. Desde la Costa Atlántica hasta la Cordillera. Terceras Jornadas Geológicas Argentinas III:123145. Buenos Aires.

Darwin, C. 1846. Geological Observations on South America. Being the Third part of the Geology of the Voyage of the Beagle, under the Command of Capt. Fitz Roy, R.N. during the Years 1832 to 1836. Smith Elder and Co., Londres.

Dewar, R.E. y K.A. McBride 1992. Remnant settlement patterns. En Space, Time, and Archaeological Landscapes, editado por J. Rossignol y L. Wandsnider, pp. 227-256. Plenum Press, New York.

Dunnell, R.C. y W.S. Dancey 1983. The siteless survey: a regional scale data collection strategy. En Advances in Archaeological Method and Theory, editado por M. Schiffer, Tomo 6, pp. $267-$ 287. Academic Press, New York.

Ebert, J. 1992. Distributional Archaeology. University of New Mexico Press, Albuquerque.

Escosteguy, L., M. Etcheverría, A. Folguera y M. Franchi 2011. Hoja Geológica 3966-IV, Choele Choel, Provincia de Río Negro, 1:250.000. Programa Nacional de Cartas Geológicas de la República Argentina. Instituto de Geología y Recursos Minerales-Servicio Geológico Minero Argentino (SEGEMAR). Boletín No 398, Buenos Aires.

Eugenio, E. y V. Aldazabal 2004. Los cazadores-recolectores del litoral marítimo del área de Bahía San Blas, provincia de Buenos Aires. En Contra Viento y Marea. Arqueología de Patagonia, compilado por M.T. Civalero, P.M. Fernández y A.G. Guraieb, pp. 687-700. Instituto Nacional de Antropología y Pensamiento Latinoamericano, Buenos Aires.

Favier Dubois, C.M. 2013. Hacia una cronología del uso del espacio en la costa norte del golfo San Matías (Río Negro, Argentina): sesgos geológicos e indicadores temporales. En Tendencias Teórico-Metodológicas y Casos de Estudio en la Arqueología de la Patagonia, editado por A. F. Zangrando, R. Barberena, A. Gil, G. Neme, M. Giardina, L. Luna, C. Otaola, S. Paulides, L. Salgán y A. Tivoli, pp. 87-96. Museo de Historia Natural de San Rafael, San Rafael.

Favier Dubois, C.M., F. Borella y R. Tykot 2009. Explorando tendencias en el uso humano del espacio y los recursos en el litoral rionegrino durante el Holoceno medio y tardío. En Arqueología de Patagonia: Una Mirada desde el Último Confín, editado por M. Salemme, F. Santiago, M. Álvarez, E. Piana, M. Vázquez y E. Mansur, pp. 985-998. Editorial Utopías, Ushuaia.

Fidalgo, F. y J.C. Riggi 1970. Consideraciones geomórficas y sedimentológicas sobre los Rodados Patagónicos. Revista de la Asociación Geológica Argentina 25:430-443.

Foley, R. 1981. A model of regional archaeological structure. Proceedings of the Prehistoric Society 47:1-17.

Forman, R.T.T. y M. Godron 1986. Landscape Ecology. Wiley, New York.

González Díaz, E. y E. Malagnino 1984. Geomorfología de la provincia de Río Negro. Publicación Especial 9:1-159. Centro de Investigaciones en Recursos, Servicio Geológico Nacional, Buenos Aires.

Gould, R.A. 1991. Arid-land foraging as seen from Australia: Adaptive models and behavioural realities. Oceania 62 (1):12-330.

Groeber, P. 1936. Oscilaciones del clima en la Argentina desde el Plioceno. Revista del Centro de Estudiantes del Doctorado de Ciencias Naturales 1 (2):71-84.

Heider, G., E. Jobbágy y A. Tripaldi 2018. Uso del espacio semiárido por poblaciones prehispánicas: El papel de los paisajes de dunas como eco-refugios en el Centro de Argentina. Boletín de la Sociedad Geológica Mexicana 71 (2):229-248.

Hercus, L. y P. Clarke 1986. Nine Simpson Desert Wells. Archaeology in Oceania 21 (1):51-62.

Hietala, A. y D. Stevens 1977. Spatial Analysis: Multiple Procedures in Pattern Recognition Studies. American Antiquity 42 (4):539-559.

Inizan, M.L., M. Reduron, H. Roche y J. Tixier 1995. Technologie de la Pierre Taillée. Cercle de Recherches et d'Études Préhistoriques, Paris.

Lyman, R. 2008. Quantitative Paleozoology (Cambridge Manuals in Archaeology). Cambridge University Press, Nueva York.

Mange, E. 2019. Investigaciones Arqueológicas en la Margen sur del Valle Medio-Superior del Río Negro (Provincia de Río Negro). Tesis doctoral inédita, Facultad de Ciencias Naturales y Museo, Universidad Nacional de La Plata, La Plata.

Mange, E., L. Prates, L. González Venanzi y M. Di Lorenzo 2016. El registro faunístico del sitio Negro Muerto 3 (provincia de Río Negro, Argentina): tafonomía y patrones de explotación. Comechingonia. Revista de Arqueología 20 (1):231-252.

Marchand, G. 1999. La néolithisation de l'ouest de la France: Caractérisation des Industries Lithiques. British Archaeological Reports, Oxford.

Martínez, G. (ed.) 2017. Arqueología de Cazadores-Recolectores del Curso Inferior del Río Colorado (Provincia de Buenos Aires, Argentina). Aportes al Conocimiento de las Ocupaciones Humanas Pampeano-Patagónicas. INCUAPA-CONICET, FACSO-UNICEN, Olavarría.

Martínez, G. y M. Gutiérrez 2019. Early Holocene water well in the Pampas of Argentina: Human responses to water shortage events. The Holocene 29 (1):145-157.

Martínez, G. y F. Santos Valero 2020. Petrographic thin sections and exotic rocks provenience among hunter-gatherers societies 
in the eastern Pampa-Patagonia transition (lower basin of the Colorado river, Argentina). Archaeometry 62 (3):493-505.

Martínez, G., F. Santos Valero, G. Flensborg, N. Carden, L. Stoessel, A.P. Alcaraz y E. Borges Vaz 2017. Was there a process of regionalisation in Northeastern Patagonia during the Late Holocene? The Journal of Island and Coastal Archaeology 12:95-114.

Meltzer, D.J. 1995. Modelling the prehistoric response to altithermal climates on the southern High Plains. En Ancient Peoples and Landscape, editado por E. Johnson, pp. 349-368. Museum Texas Tech University, Lubbock.

Munsell Colour Company Inc. 1954. Munsell Soil Colour Charts, Maryland, Baltimore.

Oría, J. y M. Salemme 2019. Shallow lake environments in the hunter-gatherer's way of life (Tierra del Fuego, Argentina). Latin American Antiquity 30 (1):109-126.

Oría, J., M. Salemme y M. Vázquez 2015. Site formation processes in relation to surface bone assemblages in the Fuegian steppe (Tierra del Fuego, Argentina). Archaeological and Anthropological Sciences 8 (2):291-304.

Orton, C., P. Tyers y A. Vince 1997. La Cerámica en Arqueología. Crítica, Barcelona.

Peralta González, S. y E. Moreno 2019. Estructuración intrasitio, registro arqueofaunístico e historia tafonómica del sitio Boliche de Jerez 3 (lago Colhué Huapi, Chubut). En Arqueología de la Patagonia: El Pasado en las Arenas, compilado por J. Gómez Otero, A. Svoboda y A. Banegas, pp. 433-431. Instituto de Diversidad y Evolución Austral, Puerto Madryn.

Prates, L. 2008. Los Indígenas del Río Negro. Un Enfoque Arqueológico. Sociedad Argentina de Antropología, Buenos Aires.

Prates, L. y E. Mange 2016. Paisajes de tránsito y estaciones en las planicies y bajos del centro-este de norpatagonia. Relaciones de la Sociedad Argentina de Antropología XLI (1):217-236.

Prates, L., G. Martínez y J.B. Belardi 2019. Los ríos en arqueología de Norpatagonia (Argentina). Revista del Museo de La Plata 4 (2):633-656

QGIS Development Team 2019. QGIS Geogarphic Information System. Open Source Geospaial Foundation Project. http:// qgis.osgeo.org.

Rice, P.M. 1987. Pottery Analysis: A Sourcebook. University of Chicago Press, Chicago.

Ringuelet, R.A. 1961. Rasgos fundamentales de la Zoogeografía de la Argentina. Physis 22 (63):151-170.

Rowlands, R.J. y J.M. Rowlands 1965. Some aboriginal wells in the western desert of Australia. Mankind 6 (5):231-237.
Rye, O.S. 1981. Pottery Technology: Principles and Reconstruction. Taraxacum, Washington D.C.

Santos Valero, F. 2017. La Gestión de Rocas a Través del Tiempo: Aportes al Estudio de la Tecnología Lítica Durante el Holoceno Medio y Tardío en el Valle Inferior del Río Colorado (Provincia de Buenos Aires). Tesis doctoral inédita, Facultad de Ciencias Sociales, Universidad Nacional del Centro de la Provincia de Buenos Aires, Olavarría.

Shepard, A. 1956. Ceramics for the Archaeologist. Carnegie Institution of Washington, Washington D.C.

Silberbauer, G. 1981. Hunter and Habitat in the Central Kalahari Desert. Cambridge University Press, Cambridge.

Svoboda, A. y E.J. Moreno 2018. Peces y coipos: zooarqueología del sitio Valle Hermoso 4 (lago Colhué Huapi, Chubut). Revista del Museo de Antropología 11 (1):85-98.

Tapia, A.H., S. Bogino, E. Dussart, A. Medina, V. Pineau, C. Landa, E. Montanari y J. Doval 2017. Tres jagüeles cercados de la pampa seca ¿cuándo y quiénes los construyeron? En Investigaciones Arqueométricas: Técnicas y Procesos, editado por A.M. Rocchietti y D. Reinoso, pp. 63-76. Aspha Ediciones, Buenos Aires.

Thomas, D.H. 1975. Nonsite sampling in archaeology: Up the creek without a site? En Sampling in Archaeology, editado por J.W. Mueller, pp. 61-89. University of Arizona Press, Tucson.

Tixier, J. 1963. Typologie de l'Épipaléolithique du Maghreb. Centre de Recherches Anthropologiques Préhistoriques et Ethnographiques, Paris.

Turq, A. 2000. Technologie lithique. Paléo, Revue d'Archéologie Préhistorique: 26-32.

Wright, D.K., M.R. Waters, C. Loendorf, M.K. Woodson, W.D. Miles y A. Darling 2013. Late Archaic wells on the Gila River Indian Community, Arizona. Journal Archaeological Science 40 (1):45-57.

Zubimendi, M.A. 2010. Estrategias de Uso del Espacio por Grupos Cazadores Recolectores en la Costa Norte de Santa Cruz y su Interior Inmediato. Tesis doctoral inédita, Facultad de Ciencias Naturales y Museo, Universidad Nacional de La Plata, La Plata.

Zubimendi, M.A. 2015. Distributional archaeology in central San Jorge gulf sector (Santa Cruz Province, Patagonia, Argentina). Quaternary International 373:104-116.

Zubimendi, M.A. y P. Ambrústolo 2017. Estudios de arqueología distribucional en Monte Loayza (Costa Norte de Santa Cruz, Patagonia). Arqueología 23 (2):99-124.

\section{Notas}

1 El análisis tecnológico solo fue llevado a cabo para el registro superficial. Esto se debió a la escasa cantidad de artefactos recuperados en estratigrafía y a que en su mayoría este registro se compone de desechos de talla de tamaño pequeño.

2 Se consideran pièces esquillées aquellos artefactos "generalmente rectangulares o cuadrados, casi siempre de muy pequeñas dimensiones, que presentan en sus dos extremidades (rara vez una sola) melladuras frecuentemente bifaciales, causadas por una percusión violenta" (Tixier 1963:146, traducción de los autores). Se caracterizan por

poseer una zona con pequeños lascados, de extensión corta y morfología escamosa, así como una zona de lascados largos, con ondas de percusión bien marcadas, resultando a menudo en piezas bifaciales (Tixier 1963).

Los filos en bisel asimétrico unifacial son aquellos instrumentos con un borde retocado de forma unifacial marginal (Armentano 2012). La delineación del filo es generalmente recta, pero puede ser también cóncava o convexa. Mayoritariamente son confeccionados sobre lascas, concoides o bipolares, de espesor y ángulo variable. 